\title{
Optical tools for ocean monitoring and research
}

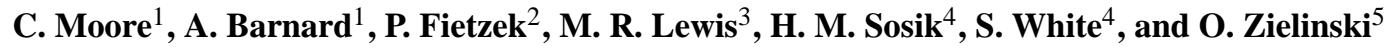 \\ ${ }^{1}$ WET Labs, Inc., Corvallis, Oregon, USA \\ ${ }^{2}$ Leibniz Institute of Marine Sciences, Chemical Oceanography, University of Kiel, Kiel, Germany \\ ${ }^{3}$ Department of Oceanography, Dalhousie University, Halifax, Nova Scotia, Canada, Satlantic, Inc. Halifax, \\ Nova Scotia, Canada \\ ${ }^{4}$ Woods Hole Oceanographic Institution, Woods Hole, MA 02543, USA \\ ${ }^{5}$ Institute for Marine Resources, University of Applied Sciences, Bremerhaven, Germany
}

Received: 29 August 2008 - Published in Ocean Sci. Discuss.: 27 November 2008

Revised: 30 November 2009 - Accepted: 30 November 2009 - Published: 10 December 2009

\begin{abstract}
Requirements for understanding the relationships between ocean color and suspended and dissolved materials within the water column, and a rapidly emerging photonics and materials technology base for performing optical based analytical techniques have generated a diverse offering of commercial sensors and research prototypes that perform optical measurements in water. Through inversion, these tools are now being used to determine a diverse set of related biogeochemical and physical parameters. Techniques engaged include measurement of the solar radiance distribution, absorption, scattering, stimulated fluorescence, flow cytometry, and various spectroscopy methods. Selective membranes and other techniques for material isolation further enhance specificity, leading to sensors for measurement of dissolved oxygen, methane, carbon dioxide, common nutrients and a variety of other parameters. Scientists are using these measurements to infer information related to an increasing set of parameters and wide range of applications over relevant scales in space and time.
\end{abstract}

\section{Introduction}

Throughout the world a significant number of research institutions and commercial entities are engaged in the research, development and manufacture of optical instrumentation for oceanographic research and observations. Two broad trends encompass many of the advances seen in today's technologies. First, many instruments have emerged from studies

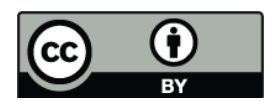

Correspondence to: $\mathrm{C}$. Moore (casey@wetlabs.com) of traditional "optical oceanography", and provide measurements and products such as determination of ocean color, scattering, absorption, attenuation, and particle concentrations. More advanced approaches now build on these fundamental observations to yield biological and chemical oceanographic related parameters such as nutrient concentrations, standing stock, productivity, particle size and composition, and taxonomic identification of organisms. Concurrently, recent advances in photonics and materials science are leading to a new generation of interdisciplinary tools emerging from the laboratory, promising broader capabilities and greater specificity in determination of in-water components as well as identification and quantification of submerged targets (e.g., seafloor mineral deposits and gas hydrates).

Most currently available commercial optical sensors rely on apparent and inherent optical properties (AOPs, IOPs) and fluorescence for various measurements. The most common of these are simple optical scattering sensors (usually sold as turbidity sensors), chlorophyll fluorometers, and PAR (photosynthetically active radiation) sensors. These sensors serve a growing role in modern environmental monitoring, although many users have only cursory understanding of the information they can provide. Another group of devices measuring AOPs or IOPs can generally be characterized as ocean color tools. These tools, including spectral radiometers (radiance and irradiance), spectral backscattering, spectral absorption, and spectral beam attenuation meters, provide in-water calibration and validation capabilities for water-leaving radiances observed with airborne and spacebased sensors. In particular, scientists are now engaged in developing inversion methods to obtain biogeochemical and physical products from these measurements. These products speak to the real potential of optical measurement in water.

Published by Copernicus Publications on behalf of the European Geosciences Union. 
Absorption meters determine nitrate concentration and identify harmful algal bloom species. Spectral fluorometers yield valuable information on phytoplankton species identification and dissolved organic chemistry. Devices that characterize the Volume Scattering Function are used to determine particle size distribution and classification. Excitation - relaxation fluorometers provide biological productivity parameters. As these tools improve and reach a broader community of users, as inversion methods and larger databases emerge, and as our need for understanding ocean processes grow, their role and impact in ocean research and monitoring will prove vital.

Advances in core photonics and materials sciences as well as embedded computing make a new realm of options available in applying optical techniques for identifying materials in the ocean. In-water flow cytometers now conduct automated and continuous sampling for periods of months to identify concentrations of multiple phytoplankton and zooplankton species. Complex spectral excitation-emission and time-resolved fluorescence tools show promise in identifying volatile hydrocarbons. Laser Raman spectroscopy, and laserinduced breakdown spectroscopy (LIBS) strive to identify the molecular and elemental composition of solids, liquids and gases in situ. Membranes and analyzers coupled with optical sensors can provide information on $\mathrm{pH}$, nutrients, dissolved gases, and metal concentrations. These tools will result in significant advances in observing ocean chemistry, biology, and geology. Optical techniques have also demonstrated the ability to determine physical parameters such as temperature, density, and turbulence, and to measure directly the absorption of solar photons that contribute to the local heating of the ocean and the development of thermal structure and dynamics. While it is unlikely that all these efforts will result in commercially viable technologies, they collectively manifest as a significant cross-cutting driver in modern observational ocean sciences.

This article reviews these existing and emerging optical technologies for in-water material and ocean state determination. It attempts to provide a sense of state of the art, and also points to promising directions. It aims to address the topic at an international level - at least within Europe and North America. As with many articles of this type, it undoubtedly fails to provide a comprehensive assessment of all on-going efforts. Previous reviews of optical oceanography and in situ sensors include Daly et al. (2004), Twardowski et al. (2005), Dickey et al. (2006), Johnson et al. (2007), Prien (2007), and Sosik (2008). The article does not address a variety of sensors and techniques used for underwater imaging of zooplankton and other materials. We refer the reader to Davis et al. (1996), Benfield et al. (2007), Jaffe et al. (2008) and Jonsson et al. (2009) for more information on this important topic. The article also does not attempt to address the recent advances in satellite-based and aircraft-based technologies and techniques - a topic deserving greater coverage.
A large body of current information regarding water based optical sensors, their use and the underlying science, exists on active internet based websites, often in the form of dynamic living documents. Many of these sites are important repositories of current information, albeit fundamentally transitory in nature. When considered of high potential use to the readers, we have included specific website references particularly to government agency sites. We hope that these sites will be of continued relevance to the readers and regret any possible inconvenience due to possible lapses or discontinuation of information that may occur.

As a final note of clarification, many of the reviewed technologies now have commercial embodiments. The authors have attempted to note these cases and provide numeric references to a manufacturers' list found at the end of this article. The authors have attempted to provide a balanced perspective in this regard, and express regret for any omissions or other mistakes made regarding relevant commercial entities. They are entirely unintentional.

\section{Inherent and apparent optical properties}

Modern fundamental optical property sensor measurements can be divided into two broad classes: apparent optical properties (AOP) and inherent optical properties (IOP). Radiance is the fundamental radiometric quantity, and varies with respect to wavelength, time, and position within a Cartesian coordinate system. Radiance varies as well with angular direction (azimuth and zenith). AOP's vary as the angular radiance distribution varies; sensors measuring these properties are in general passive, using the sun as their source. In contrast, IOP measurements are insensitive to the ambient radiance field, and generally employ an active source. Figure 1 shows some basic schematic embodiments of these devices.

As a set of technologies, AOP devices hold some desirable attributes (see Lewis, 2008). The fundamental AOP measurements of radiance and irradiance are directly traceable to agreed-upon and readily available international standards appropriate for use in the ocean environment. For the derivation of diffuse attenuation and reflectance, in principle, only relative measurements are required (e.g., measuring the vertical gradient in irradiance); hence precise, but not necessarily accurate, measurements can provide useful information from their vertical gradients from which advanced inversion techniques can be used to derive IOP and water constituents. Passive detection of sunlight results in relatively low energy consumption, and implies that AOP sensors measure light levels experienced by the surrounding biota. Finally it is important to note that measurements of radiance and irradiance, and the derivation of diffuse attenuation coefficients and reflectances, have been extensively examined by the oceanographic community and have resulted in a consensus with respect to a detailed set of protocols and approaches for design, characterization, calibration, at-sea deployment, 

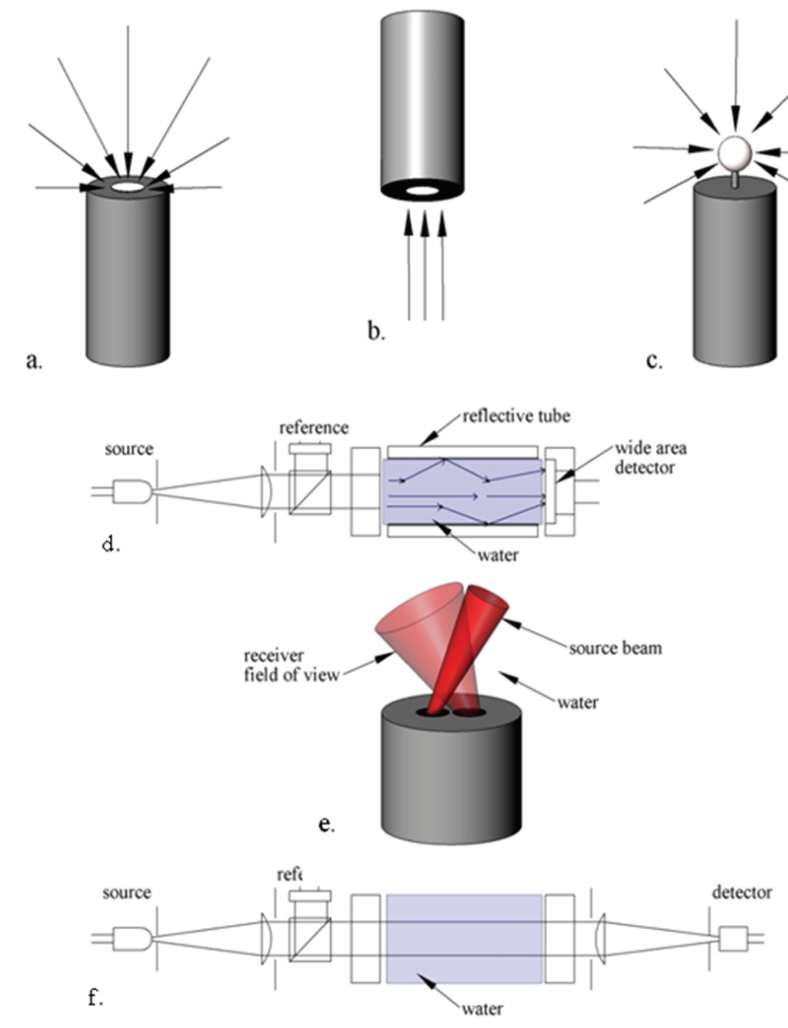

Fig. 1. Schematic representations for common AOP and IOP sensors: (a) irradiance meter; (b) radiance meter; (c) scalar irradiance meter; (d) reflective tube absorption meter; (e) backscattering sensor; and (f) transmissometer (beam attenuation meter).

and data analyses associated with AOP instruments for the ocean measurements (see Mueller et al., 2003).

In contrast to AOP sensors, IOP sensors use a light source of defined intensity, angular distribution, and spectral bandwidth (see Roesler and Boss, 2008). This, in turn, allows one to derive absolute coefficients of optical transfer properties, including the beam attenuation coefficient (indicating total light lost to scattering and absorption over a given path of travel in the water), the absorption coefficient (indicating light lost to absorbing particles and dissolved matter) and various scattering properties within the measured sample volume. Similarly to AOPs, the IOP devices have some desirable attributes. They can be used at any time of day, and are not subject to variable cloud cover, surface conditions, ship shadows and other issues sometimes associated with AOP measurements. IOP devices measure over relatively short pathlengths and can resolve in-water variability at scales ranging down to a few centimeters (Twardowski et al., 2005). They also do not require inversions to obtain optical coefficients. While designs for devices that measure IOPs differ, they generally fall into two broad groups: first, devices that determine transmittance losses through a fixed path or volume of light; and second, devices that rely upon coupling of a source emitter and a receiver-detector set at opposing angles with a defined volume of intersection. With the exception of turbidity meters and transmissometers, most commercial IOP devices were developed relatively recently and their use is less widespread than their AOP counterparts. The transmissive devices are quite sensitive to light level changes and thus can require precise calibration procedures, careful cleaning, and reasonable care in deployment. Protocols for effective use of IOP have also been developed and published (Mueller et al., 2003).

Both AOP and IOP sensor technologies and associated methods hold advantages and limitations, but fundamentally the two systems of measurement are complementary and synergistic. The measurements are tightly interrelated, providing some possibilities for consistency checks, but also with each providing distinct insights (Fig. 2).

\subsection{Radiometers, irradiance sensors and PAR sensors}

Instruments used for AOP determination can be broadly classified with respect to the angular integration performed by the foreoptics. Narrow angular field-of-view sensors measure radiance, while flat plates can provide cosine weighting to yield planar irradiance, and spherical collectors, which weight all directions equally, measure scalar irradiance. All of these can be manufactured in multi-spectral (limited number of wavebands) and hyperspectral (a large number of narrow wavebands, typically hundreds, see Chang et al., 2004) configurations to provide full spectral distribution over the ultraviolet (UV), visible and near infrared bands. For some applications, spectral weighting filters are employed to return the integral energy or number of photons over the entire visible spectrum (400-700 nm); these are often sold as PAR sensors. While most commercial AOP sensors use a limited portion of the radiance distribution, Voss and Chapin (2005), and Aas and Højerslev (1999) and others have developed devices that measure the radiance distribution over large angular ranges. This not only provides a basis for determination of important AOP parameters, such as upward radiance and planar irradiance, but also potentially provides a means to derive IOPs through inversion (e.g., Zaneveld and Pak, 1972; Gordon et al., 1975; and Voss, 1989). Trade-offs in design of AOP sensors include spectral and angular discrimination, number of wavebands, sensitivity, dynamic range, and effective sample rates (Twardowski et al., 2005).

A special application of radiance measurements is the determination of chlorophyll biomass and photosynthetic capacity via the measurement of the red $(683 \mathrm{~nm})$ fluorescence resulting from absorption of ambient sunlight. This topic has been well-reviewed recently (Babin et al., 1996; Babin, 2008); the approach has been successfully applied to both in situ and remote observations (see Huot et al., 2005).

AOP sensors are now engaged routinely and operationally for applications including remote sensing validation and calibration (Gordon, 1998; Werdell and Bailey, 2005; Bailey et al., 2008) and in capturing optical changes associated with 

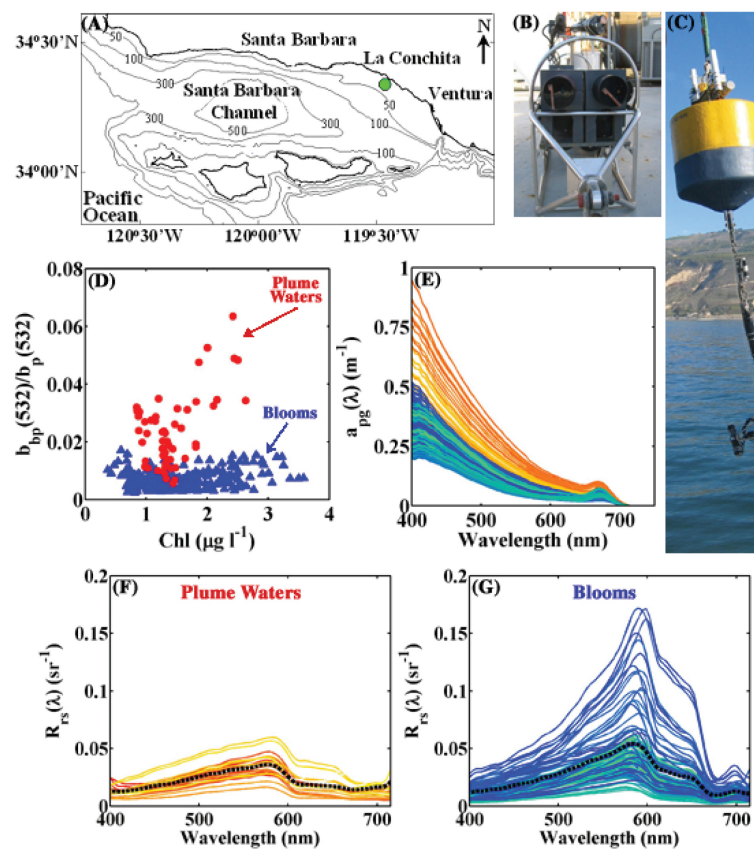

Fig. 2. Combined IOP-AOP based monitoring effort shows: (A) map of the Santa Barbara Channel; CHARM location indicated by green dot. (B) Photograph of a bio-optical sensor system showing copper anti-biofoulant "Bio-Wipers" on spectral fluorescence and backscattering sensors. (C) Photograph of the CHARM deployment; sensor package shown was deployed at $4 \mathrm{~m}$ water depth. (DG) show CHARM data collected in February and March 2004 during advection of the Ventura River plume from winter storm runoff (shown in reds and oranges) and during phytoplankton blooms (shown in blues and greens). (D) Backscattering ratio versus chlorophyll concentration. High values of bbp/bp indicates higher concentrations of minerogenic particles and higher values of Chl denote the presence of phytoplankton. (E) Hyperspectral absorption spectra measured by an $a c-s$. Note the extremely high variability in spectral signatures due to plume waters and blooms. (F) and (G) Hyperspectral remote sensing reflectance spectra, also exhibiting strong variability. Dashed, black lines are spectral means (contributed by Grace Chang-Spada, University California, Santa Barbara).

episodic events (Chang et al., 2006). Principal manufacturers of AOP sensors for use in the ocean environment include several companies $(4,11,12,15,20)$.

\subsection{Attenuation and absorption meters}

Beam attenuation meters, commonly referred to as transmissometers, operate upon the principle of propagating a collimated beam of light through a path length of water. The natural logarithm of the ratio of light intensity at the source versus the receiver, I/Io, is equal to the beam attenuation coefficient, $c$, multiplied by the optical path length, $r$, or $\mathrm{I} / \mathrm{Io}=e^{-c r}$ (Jerlov, 1978). Modern transmissometers for in situ ocean research were made commercially available in the 1970s (Bartz et al., 1978). Systems now exist that operate at single wavelengths, multiple wavelengths, and hyperspectrally (Moore et al., 2004). These devices are now used to estimate visibility (Zaneveld, 2003), particulate organic carbon (e.g., Bishop, 1999) species composition (Claustre et al., 2008) and in other applications to characterize suspended particles in water (Twardowski et al., 2005). Twardowski et al. (2002) recently developed a beam attenuation meter that measures optical backscattering from a single source at two different path distances. The flat-faceplate form factor makes this configuration useful for integration on AUVs and gliders. Commercial devices are available from various manufacturers $(5,10,17,22)$.

While the beam attenuation coefficient pertains to the total light loss through a given path of water, the absorption coefficient is associated with those losses due only to the molecular absorption of the water and the components contained therein. In combination, these measurements combine to offer powerful capabilities in classifying in situ materials. Measured over multiple wavelengths the absorption spectra of some materials provide unique signatures. Moreover absorption coefficients for complex media of dissolved materials $\left(a_{g}\right)$ (where $g$ denotes gelbstoff, also referred to as CDOM or gilvin, see Kirk, 1994), and particulate materials $\left(a_{p}\right)$, can be deconvolved so that, $a_{g}+a_{p}+a_{w}=a_{t}$; where, $a_{w}$, and $a_{t}$, represent the absorption coefficients for water and the total absorption coefficient, respectively (Jerlov, 1978). Thus with appropriate sampling techniques one can specifically apply absorption meters to obtain these partitioned parameters (Mueller et al., 2003), (Fig. 3). While generally still based upon a transmittance measurement, the conceptual framework behind underwater absorption meters is based on minimizing measurement losses due to highly scattering media found in natural waters, in order to retrieve the absorption components.

There are a few different approaches to design of modern absorption meters. Reflective tube absorption meters use a collimated beam propagating through a fixed path surrounded by a reflective tube and impinging upon a large area detector (Moore et al., 1992). The reflective tube and the wide area detector serve to collect the transmitted light as well as light that is scattered by particles in the near forward direction. Since the forward scattered light represents $80-90 \%$ of the total, the transmittance losses approximate losses due to absorption such that the absorption coefficient can subsequently be estimated to within a 5 percent of total scattered light through a proportional attenuation based correction (Zaneveld, 1994). Commercial units incorporating this design are available in multi-spectral and hyperspectral configurations (22). Developed in original form by Fry et al. (1992), and then advanced by Kirk (1997), the Point Source Integrating Cavity Absorption Meter (PSICAM), is designed to detect absorption spectra in an integrating cavity sphere filled with untreated natural water. The principle is based on multiple reflection and scattering, and thus the extension of the path length. This inherently provides a 

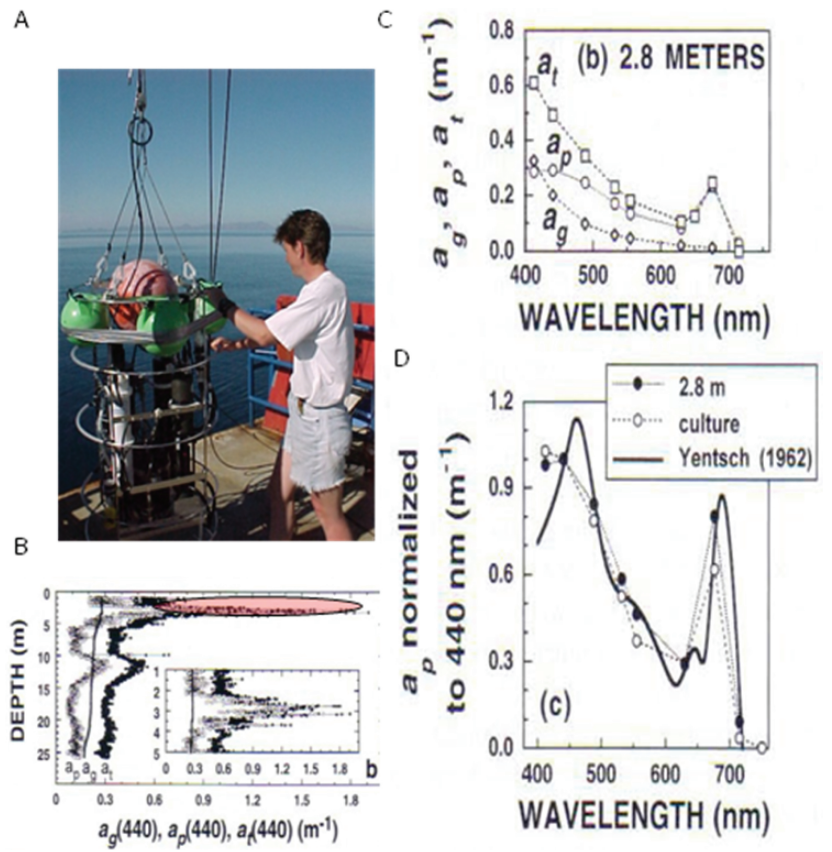

Fig. 3. (A) The Oregon State University optical profiling system incorporates two multi-spectral attenuation and absorption meters - one with a 0.2 micron filter at inlet partition dissolved absorption coefficient $\left(a_{g}\right)$. Floats are used to achieve slow freefall descents for sampling. (B) Profile obtained at East Sound, Washington shows partitioned absorption coefficients through fine scale particle maxima. (C) Figure shows partitioned absorption spectra in the particle maximum. (D) In situ absorption spectra coefficients of a layer dominated by Chaetoceros eibenii $(\mathrm{Ce})$, spectrum obtained from laboratory culture of $\mathrm{Ce}$ using in situ sensor, and $(\mathrm{Ce})$ culture measured using filter pad method with laboratory spectrophotometer (from Yentsch, 1962) Data and figures from Twardowski et al. (1999).

reduction of scattering effects on absorption because the light field is already diffuse inside the cavity. Röttgers and Doerffer (2007) demonstrated the possibilities of the PSICAM for the absorption of CDOM and the particulate absorption of microalgae (Röttgers et al., 2007). A commercial, submersible version of this design was introduced in the USA in 2006 (Dana et al., 2006) and in 2008 a version of the PSICAM was recently made available by a German sensor manufacturer $(11,20)$.

Researchers at Mote Research Laboratories used a liquid capillary tube design to produce a hyperspectral absorption meter that serves a dedicated purpose in identification and detection of harmful algal blooms species. The sensor has shown unique application in identifying Karenia brevis, an organism that commonly causes harmful algal blooms off the coast of Florida (Kirkpatrick, 2006). Built for operation on AUVs, the instrument is transitioning from a research device to a monitoring tool.
Johnson and Coletti (2002) developed a 1-cm path hyperspectral absorption sensor for operation in the UV at a sampling rate of $1 \mathrm{~Hz}$. This sensor uses a unique multiwavelength differential method to separate nitrate from a background of various salts and organic matter and has been used to establish large-scale rates of new production in the ocean (Johnson et al., 2006). One vendor (15) provides commercial devices based on this design, while others use related technologies (e.g., 20). The optical approach for nitrate analysis is used both in real-time and extended monitoring applications throughout the world. Accuracy and long-term stability of this approach can be further improved if the degrees of freedom within the algorithms are reduced by externally measured temperature and salinity information (Zielinski et al., 2007; Sakamoto et al., 2009).

\subsection{Scattering sensors}

When light is scattered by a particle it propagates in all directions. The relative distribution of light throughout the various angles of scattering is defined by the Volume Scattering Function (VSF). The relative magnitude, spectral shape and angular distribution of the VSF is, in turn, influenced by the concentration, size, composition and shape of the particles (Jerlov, 1978). Scattering sensors take advantage of these VSF attributes by measuring over certain spectral and angular regions of the VSF to infer particle information.

Turbidity sensors are among the most common optical sensors, and are widely available for ocean based applications $(1,2,16,21,22,23,24)$. These sensors play an increasingly important role in operational oceanographic monitoring and many of the commercial embodiments have undergone independent performance verification (e.g. Alliance of Coastal Technologies, 2006). Turbidity sensors provide an indication of suspended particle concentrations, through optical scattering, generally centered around 90 degrees from the primary beam axis of propagation (Greenburg et al., 1992). Turbidity sensors are calibrated against a secondary standard suspension (e.g., formazin) and output is expressed in units relative to the standard. The sensors come in a variety of configurations and these differences tend to lead to different responses in different water masses, due to measuring different parts of the VSF and potential absorption effects (Zaneveld et al., 1979). There are numerous methods and configuration standards (e.g., ISO 7027) for turbidity sensors.

While the underlying measurements are similar to turbidity sensors, backscattering sensors used in ocean color studies provide output in absolute coefficients related to the portion of VSF they observe. Scattering is the dominant interaction mechanism between light and particles in most natural waters, and light scattered between 90 and 180 degrees (typically referred to as the backwards direction) is proportional to the signal seen by satellites. Single-angle optical backscattering sensors are configured for measurement typically between 115 degrees and 145 degrees (some special 
Table 1. Commercial manufacturer list.

\begin{tabular}{|c|c|c|c|c|}
\hline Ref & Vendor & Web link & Relevant Products or Sevices & Location \\
\hline 1 & Aanderaa Data Instruments & www.aadi.no & Optodes & Norway \\
\hline 2 & JFE ALEC & www.jfe-alec.co.jp & $\begin{array}{l}\text { Fluorometers, spectral fluorome- } \\
\text { ters, turbidity sensors }\end{array}$ & Japan \\
\hline 3 & bbe Moldaenke & www.bbe-moldaenke.de & Spectral fluorometers & Germany \\
\hline 4 & Biospherical Sensors & www.biospherical.com & Spectral radiometers, PAR & USA \\
\hline 5 & Chelsea Technologies Group & www.chelsea.co.uk & $\begin{array}{l}\text { Transmissometers, fluorometers, } \\
\text { excitation emission fluorometers }\end{array}$ & Great Britain \\
\hline 6 & $\begin{array}{l}\text { Contros Offshore Systems and } \\
\text { Solutions }\end{array}$ & www.contros.eu & Optical membrane gas sensors & Germany \\
\hline 7 & Cytopeia & www.cytopeia.com & Sea-going flow cytometers & USA \\
\hline 8 & CytoBuoy & www.cytobuoy.com & $\begin{array}{l}\text { Sea-going and submersible flow cy- } \\
\text { tometers }\end{array}$ & The Netherlands \\
\hline 9 & Fluid Imaging Technologies & www.fluidimaging.com & Flow cytometers & USA \\
\hline 10 & Fugro-Oceanor & www.oceanor.no & Spectral transmissometers & Norway \\
\hline 11 & Hobi Labs & www.hobilabs.com & $\begin{array}{l}\text { Spectral backscattering sensors, } \\
\text { spectral radidiometers, spectral } \\
\text { absorption meters }\end{array}$ & USA \\
\hline 12 & Li-Cor Biosciences & www.licor.com & PAR sensors & USA \\
\hline 13 & ODIM Brooke Ocean & www.brooke-ocean.com & Optical planton counters & Canada \\
\hline 14 & Pro Oceanus & www.pro-oceanus.com & Optical membrane gas sensors & Canada \\
\hline 15 & Satlantic & www.satlantic.com & $\begin{array}{l}\text { Spectral radiometers, PAR, } \\
\text { excitation-relaxation fluorome- } \\
\text { ters, optical nitrate sensors }\end{array}$ & Canada \\
\hline 16 & Seapoint Sensors & www.seapoint.com & Fluorometers, scattering sensors & USA \\
\hline 17 & Sequoia Scientific & www.sequoiasci.com & $\begin{array}{l}\text { VSF, particle size distribution sen- } \\
\text { sors }\end{array}$ & USA \\
\hline 18 & Sunburst Sensors & www.sunburstsensors.com & $\begin{array}{l}\text { Automous analyzers for } \mathrm{pCO}_{2}, \mathrm{pH} \text {, } \\
\text { total Alkalinity }\end{array}$ & USA \\
\hline 19 & Teledyne Benthos & www.benthos.com & Bioluminescence sensors & USA \\
\hline 20 & TriOS & www.trios.de & $\begin{array}{l}\text { Spectral radiometers, spectral ab- } \\
\text { sorption meters, optical nitrate sen- } \\
\text { sor, fluorometers }\end{array}$ & Germany \\
\hline 21 & Turner Designs & www.turnerdesigns.com & Fluorometers, spectral fluorometers & USA \\
\hline 22 & WET Labs & www.wetlabs.com & $\begin{array}{l}\text { Transmissometers, fluorometers, } \\
\text { spectral fluorometers,spectral } \\
\text { backscattering sensors, spectral } \\
\text { absorption and attenuation meters, } \\
\text { vsf sensors, reagent analyzers }\end{array}$ & USA \\
\hline 23 & YSI & www.ysi.com & $\begin{array}{l}\text { Fluorometers, turbidity, DO, } \\
\text { reagent analyzers }\end{array}$ & USA \\
\hline 24 & $\begin{array}{l}\text { Campbell Scientific Inc-D \& A } \\
\text { Instruments Co. }\end{array}$ & www.d-a-instruments.com & Turbidity & USA \\
\hline 25 & Group Martec & www.martec.fr & $p \mathrm{CO}_{2}$ & France \\
\hline 26 & Enviro Tech Instruments & $\begin{array}{l}\text { www.envirotechinstruments. } \\
\text { com }\end{array}$ & Reagent analyzers & USA \\
\hline 27 & Subchem Systems & www.subchem.com & Reagent analyzers & USA \\
\hline 28 & Systea & www.systea.it & Reagent analyzers & Italy \\
\hline
\end{tabular}

configurations center closer to 180 degrees). These sensors are calibrated in absolute terms relating to the angular region defined by the source-receiver interaction volume and, or in response to particles with a known VSF (Maffione and Dana, 1997). Usually the coefficients are for the scattering at a spe- cific angle or are extrapolated to estimate scattering in the entire backward region (90-180 degrees). Currently within the United States, two manufacturers produce these sensors - both come in multi-spectral configurations $(11,22)$. These sensors are most widely used in applications focused upon 
validating ocean color measurements from satellites (e.g., Tzortziou et al., 2006).

Similarly to radiometric measurements, most scattering measurements characterize only a small component of the entire VSF - generally only one angle. Sensors that measure over multiple angles are rarer. In fact, these measurements are made so seldom that scientists continue to rely significantly on historical data sets obtained over 30 years ago (e.g., Petzold, 1972). Even today only a few embodiments of multi-angle scattering sensors exist. Moore et al. (2000) developed a 3-angle backscattering device for more accurate estimation of the total backscattering coefficient (22). Agrawal (2005) developed and commercialized a near-forward-angle multiple-angle scattering device from which it is possible to invert for particle size distributions (18). In 2002 scientists and engineers from the Ukraine, partnering with Canadian and American colleagues, introduced a new device for VSF determination. The sensor measures scattering at 0.3 degree resolution from 0.6 degree in the near forward to 177.3 degree in the backward direction (Lee and Lewis, 2003). Twardowski (2009) recently tested a new device which captures 10 degree resolution full VSFs at $20 \mathrm{~Hz}$ repetition rates to observe scattering in a dynamic environment such as bubble injection from surface wave collapse. Near forward scattering from $0-0.1$ degrees becomes dominated by small scale variations in the water density. Exploiting this phenomenon Bogucki et al. (2007) incorporated a wavefront sensing Shack-Hartmann lenslet array and a 2000 element, rapidly scanning, linear photo-diode array to measure near forward optical scattering. They then inverted this information to determine the in-water turbulence. An in situ prototype of this sensor has now been developed and tested.

\subsection{Platforms and applications}

While the subject of modern deployment platforms was covered recently by Dickey et al. (2008), their roles in enabling IOP and AOP measurements merits mention. In the last several years, an interesting range of platforms has been developed or modified for in-water optical oceanographic instrumentation, augmenting more conventional ship-based measurements (see Dickey et al., 2006; and Twardowski et al., 2005). These include a range of vehicles, floats, and mooring designs that can be thought of as complementary, as each has its own temporal and spatial scales over which the observations can be made. Sampling strategies that integrate multiple platforms can therefore be very effective (e.g., Dickey et al., 2006). In addition, there are sensors coupled with application-specific platforms. These are often necessary to decouple ship shadows and other platform effects (Waters et al., 1990). These include free-fall profilers, surface floats that provide reflectance measurements, and multiple irradiance units placed at different vertical depths on moorings for determination of diffuse attenuation coefficients and various reflectances. Above-water measurements, which view the surface ocean, also have applications. For example, ships of opportunity can be instrumented (see Balch et al., 2004), or instruments deployed on buoys, docks or towers (e.g., Zibordi et al., 2002). These instruments by their nature are restricted to direct measurement of AOPs only, and specifically the reflectance of the sea surface. A critical sampling objective for determining biological variability through the water column lies in being able to sample the water over centimeter spatial scales without disturbing the natural distribution of matter. Numerous free-falling integrated packages and tethered autonomous profilers have been developed to address these challenges (e.g., Donaghay et al., 2002). In recent years, there has been a general surge in the development of new autonomous vehicles for the measurement of a wide range of oceanographic properties. These include profiling floats under the global ARGO program (e.g., Wilson, 2000), the use of powered autonomous underwater vehicles (AUVs) with conventional propulsion methods (Griffiths et al., 2001) and hybrid vehicles such as gliders that combine the buoyancy control of profiling floats with mechanisms for controlling vertical position (e.g., Davis et al., 2002). Optical instruments have seen limited but growing deployment on such platforms (e.g., Mitchell et al., 2000; Bishop et al., 2002; Cunningham et al., 2003; Zielinski et al., 2006; and Boss, 2008). Figure 4 illustrates some recent applications of autonomous platforms equipped with optical sensors.

\section{Fluorescence and bioluminescence sensors}

Fluorescence and bioluminescence are processes that while much different from each other, emit light as a result of some stimulus. Light absorbed by organisms containing chlorophyll (and ancillary pigments), colored dissolved organic material, various hydrocarbon materials, optical brighteners for detergents, and dyes can excite electrons in the given materials, resulting in photo-emission or fluorescence. Fluorescence from a given material is characterized by specific excitation wavelengths triggering specific emission wavelengths (see Babin, 2008). This property in turn, can be used to detect and identify materials, estimate concentrations, and provide invaluable physiological information for phytoplankton and algal materials. Similarly, certain organisms emit light when mechanically agitated. This phenomenon is known as bioluminescence. Bioluminescence sensors can be used to detect and identify types of organisms in the water.

\subsection{Single channel fluorometers}

In situ single channel fluorometers can be configured for detection of colored dissolved organic matter (CDOM), chlorophyll and ancillary pigments, and other anthropogenic materials; these are widely available in various commercial embodiments $(1,2,3,5,16,20,21,22,23)$. Many come with built in bio-fouling protection (e.g., Manov, 2004). These 
A

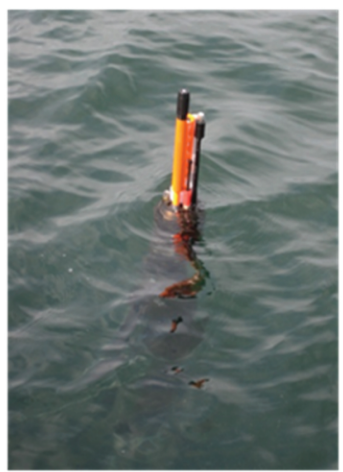

C

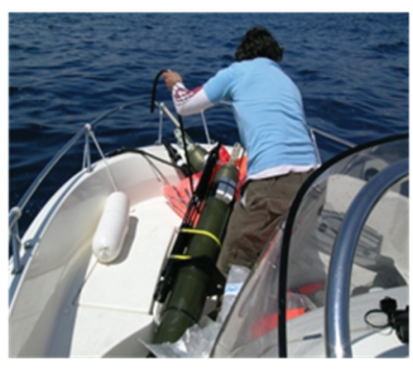

B

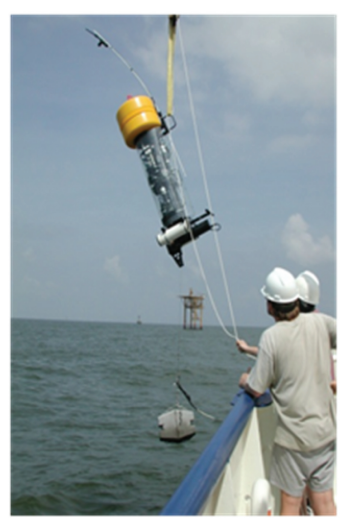

D

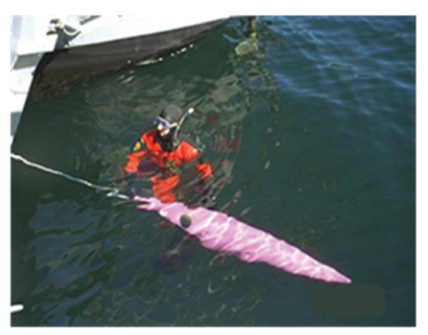

Fig. 4. (A) NEMO profiling float with radiometer deployed in North Sea. (B) University of Rhode Island developed ORCAS autonomous moored profiler with spectral absorption and attenuation meter, chlorophyll fluorometer, and backscattering sensor. (C) PROVOR float with integrated AOP-IOP sensor prepared for deployment in Mediterranean Sea. (D) University of Washington developed Sea Glider autonomous glider with scattering sensor during deployment.

units are relatively inexpensive, independently evaluated (e.g., ACT, 2005) and provide reasonable proxies for phytoplankton concentration variability. While somewhat effective in this capacity they are subject to various sources of uncertainty, including physiological effects (Kirk, 1994), photoacclimation of phytoplankton, photo-bleaching of CDOM (Twardowski, 2002), and other ecological and environmental factors. Another issue associated with these devices is that different instruments use different excitation sources, different excitation frequencies and different excitation intensities, which, coupled with physiological variation, make interpretation and, in particular, intercomparison difficult. There is a clear need for standardization of calibration procedures and processes among manufacturers (ACT, 2005).

\subsection{Spectral fluorometers}

As with absorption meters, fluorometers that resolve spectral excitation and/or emission provide a greater potential for identification of biological particles and chemical compounds. Several manufactures now provide multi-spectral fluorometers for detection of chlorophyll and some of its ancillary pigments as well as $\operatorname{CDOM}(2,3,21,22)$. These systems tend to match excitation-emission wavelengths to provide optimal fluorescence response for given pigments and other organic compounds. In ecosystems in which there are characteristic species this information can, in turn, be used to infer taxonomic composition (e.g., Beutler et al., 2002). Using multiple spectral excitation and emission bands to produce identifying signatures is carried to the next step in some recently developed research prototypes. These sensors couple single or multi-excitation sources with spectrometerbased emission receivers. Cowles et al. (1993) developed one of the first of this class of device, combining three excitation bands with a spectrometer-based emission measurement. Since that time, both the component technologies and final products have evolved. Chekalyuk et al. (2006) developed a laser-based-excitation, high-resolution-spectrometer emission fluorometer for CDOM and phytoplankton emission, including coupling measurements with deconvolution software to identify specific phytoplankton types. Another example uses multispectral excitation throughout the UV region coupled with spectrometer-based emission measurement to provide 2-dimensional excitation-emission matrices (EEM) (Moore et al., 2004). The EEM are subsequently processed with a parallel factor analysis method to deconvolve specific hydrocarbons and CDOM species.

\subsection{Excitation relaxation fluorometers}

By monitoring the induction and decay of chlorophyll $a$ fluorescence over microsecond to millisecond timescales and in response to carefully controlled excitation intensity and duration, it is possible to characterize photosynthetic properties of phytoplankton (e.g., Kolber et al., 1998). These so-called "variable" chlorophyll $a$ fluorescence approaches include pump and probe methods, pulse amplitude modulation (PAM), fast repetition rate (FRRF), pump-during-probe (PDP) and fluorescence induction and recovery (FIRe); the methods differ effectively in how the light pulse is applied to saturate photosystem II (PSII) photochemistry and in the details of the resulting emission measurements. The derived parameters include the maximum quantum yield as well as the effective yield, from which the photosynthesisirradiance curve can be estimated and used to calculate primary productivity. These approaches have been reviewed by Röttgers (2006) and devices are now manufactured in laboratory modes, onboard underway instruments, and in situ versions and are produced by multiple manufacturers $(3,5$, $15,21)$. 


\subsection{Time resolved fluorescence}

The radiative relaxation of a molecule from an excited state $\mathrm{S}_{\mathrm{x}}$ to a low state $\mathrm{S}_{\mathrm{x}-n}$ is called fluorescence and is, in most cases, a spontaneous emission. The fluorescence lifetime $\kappa$ refers to the average time the molecule stays in the excited state before emitting a photon, following typically an exponential $\left[\mathrm{S}_{\mathrm{X}}\right](t)=\left[\mathrm{S}_{\mathrm{x}}\right]_{0} \cdot \exp (-t / \kappa)$ or multi-exponential decay where $\left[S_{X}\right](t)$ is the concentration of excited state molecules at time $t$ and $\left[\mathrm{S}_{\mathrm{x}}\right]_{0}$ is the initial concentration. The fluorescence lifetime is dependent on the molecular kinetics and is therefore characteristic information that can be used to distinguish substances in complex media. For example, hydrocarbon steady-state fluorescence can be very similar in its spectral shape to CDOM fluorescence, both excited by UV radiation. However, the fluorescence life time for the components differ: light oils show slower decay of up to $60 \mathrm{~ns}$ (Rayner and Szabo, 1978), while CDOM decay occurs in less than $10 \mathrm{~ns}$ (Clark et al., 2002), and crude oil ranges from $2 \mathrm{~ns}$ to $20 \mathrm{~ns}$ (Ryder, 2002). There is a dependency between the excitation wavelength, the substance concentration and the fluorescence lifetime observed. For volatile compounds and polycyclic aromatic hydrocarbons, sub-nanosecond excitation in the middle ultraviolet spectrum $(200-300 \mathrm{~nm})$ is required. Time-resolved laboratory and process-control systems are available (e.g., Bublitz et al., 1995), and a submersible time-resolved fluorescence decay sensor, combined with a hyperspectral fluorometer, is currently under development (Rohde et al., 2009).

\subsection{Bioluminescence sensors}

Bioluminescence (BL) probably occurs at all depths and locales in the ocean. Its importance to marine organisms is emphasized by biochemical evidence that BL evolved independently at least 30 times in the sea (Wilson and Hastings, 1998). BL is widespread in bacteria, both free-living and symbiotic forms, while BL of independent origin occurs in 15 phyla from dinoflagellates and radiolaria through teleost fish (Herring, 1987). It is conspicuously present in both auto- and heterotrophic dinoflagellates, protochordates, the Cnidaria, all but one species of the Ctenophora (combjellies) (Haddock and Case, 1999), and all the major groups of crustaceans in surface and mid-waters. In the pelagic realm, BL is so widely distributed that it is a useful relative index of biomass (e.g., standing stock) and for some purposes can replace standard volumetric, gravimetric and microscopic enumeration of plankton tows or pumped samples (Lapota, 1998; Piontkovski et al., 1997). BL measurement may also provide a complement to modern acoustic methods for biomass estimation (Holliday, 2001).

Sensors used to detect BL come in a variety of designs and sizes. They include large profilers and towed bodies for complete capturing of both small and larger organisms (Widder and Johnson, 1998; Widder et al., 2005), buoy systems for real-time monitoring (Lapota, 2003), free fall passive sensors, and general purpose meters for deployment on moorings, profilers and other unattended platforms (Herren et al., 2005; and Haddock et al., 2005). Widder (2006) provides a historical perspective in reviewing the development of bioluminescence science and technology. There are currently two known commercial suppliers $(5,19)$.

\section{Flow cytometry}

Among methods for characterizing the optical properties of individual particles, flow cytometry is almost certainly the most prevalent in oceanographic research. Since the midto late 1980s, it has enabled important new discoveries and insights, especially in areas of plankton ecology (Sosik et al., 2009). One indication of the prevalence and impact of flow cytometry has been the appearance of special journal issues focused on applications in aquatic sciences (Yentsch and Horan, 1989; Reckermann and Colijn, 2000; Courties and Troussellier, 2001). Focus on in situ applications is now emerging with several manufacturers supplying relevant products $(7,8,9)$ and new systems are under development.

Flow cytometers measure light scattering and fluorescence properties of individual particles as they pass through a focused light source (often a laser beam). The particles are carried in a fluid stream (e.g., seawater for marine samples) in the center of a particle free sheath which is flowing at high speed ( $\sim 1-10 \mathrm{~m} \mathrm{~s}^{-1}$ typical) perpendicular to the illumination beam. Sample fluid is injected into the sheath in such a way that hydrodynamic focusing leads to particles flowing in single file as they intersect the beam. Light scattering and fluorescence signals originating from each particle are measured with detectors (typically photomultiplier tubes) positioned around the sensing region, with lenses and/or detector geometry defining the collection angles. In specially designed flow cytometers, it is possible to physically sort particles on the basis of their light scattering and fluorescence characteristics. Shapiro (2003) provides a thorough consideration of flow cytometry measurement and analysis principles.

While bio-medical uses for flow cytometry usually involve treatment of cells with fluorescent dyes or probes prior to analysis, the most common oceanographic applications have focused on measurement of phytoplankton cells, which naturally exhibit fluorescence associated with their photosynthetic and certain light harvesting pigments. For typical phytoplankton studies, the excitation wavelength is within the blue or blue-green region of the spectrum and configurations include measurement of red fluorescence (associated with chlorophyll) and orange fluorescence (associated with phycoerythrin), plus light scattering from a range of near forward angles and side angles (i.e., near right angle from incident). Variations include addition of green fluorescence, detection of polarized scattered light, and use of dual excitation beams 
(Olson et al., 1988, 1989). More details can be found in a number of reviews (e.g., Olson et al., 1993; Campbell, 2001; Marie et al., 2005).

In general, flow cytometry measurements of phytoplankton permit enumeration, quantification of cell properties such as size and pigmentation, and some level of taxonomic or sized-based discrimination (e.g., Synechococcus, picoeukaryotes, coccolithorids) (e.g., Olson et al., 1989, 1990b). With analyses that include use of stains or probes, flow cytometry can be used for further assessments such as nucleic acid content, cell cycle status and growth rate (e.g., Chisholm et al., 1986; Vaulot et al., 1995; Marie et al., 1997), cell viability (e.g., Jochem, 2000; Veldhuis et al., 2001), and enumeration of other microbes such as heterotrophic bacteria, viruses, and protozoa (e.g., Marie et al., 1997, 1999; Li and Dickie, 2001; Rose et al., 2004; Zubkov et al., 2007).

Commercial, laboratory based, flow cytometers are generally optimized for biomedical or clinical requirements with relatively narrow ranges of signal amplitudes and for use with high particle concentrations. Consequently, many oceanographic uses require modifications (e.g., custom sample pumps, dual sheath, dual photomultipliers) to increase sample throughput and dynamic range of signals (e.g., Cavender-Bares et al., 1998; Green et al., 2003; Zubkov and Burkhill, 2006). In addition, because commercial instruments often lack the sensitivity to quantify fluorescence from picophytoplankton cells (especially those growing in high light environments that lead to low cellular pigment levels), customized optics and high laser power configurations have been adapted (e.g., Frankel et al., 1990; Olson et al., 1990a). Resulting systems are typically well suited for quantifying particles in the pico- to small nanoplankton size range $(\sim 1-$ $10 \mu \mathrm{m}$ ), though with specialized developments the range can be shifted (for instance towards larger, more rare particles as in the application depicted in Fig. 5 where microplankton up to several $100 \mu \mathrm{m}$ can be quantified).

Soon after its introduction into oceanography, the impact of flow cytometry was greatly stimulated by shipboard operation of laboratory instruments (e.g., Olson et al., 1985, 1990b; Li, 1989). Not only did this development permit assessment of spatial and temporal variability at important scales, but it also led to paradigm-shifting discovery, most notably in the case of Prochlorococcus (Chisholm et al., 1988; Olson et al., 1990a). Other noteworthy advances in shipboard use include implementation of cell sorting (O1son et al., 1991; Reckermann, 2000), development of singlecell fluorescence induction measurements for photosynthetic assays (Olson et al., 1999; Sosik and Olson, 2002), and progress in building quantitative links between single particles and bulk optical properties (DuRand and Olson, 1996; Green et al., 2003; Green and Sosik, 2004).

Despite the rapid and quantitative analysis of particles permitted by shipboard flow cytometry, sampling constraints continue to limit conventional applications. Analysis remains relatively labor-intensive and is confined to samples

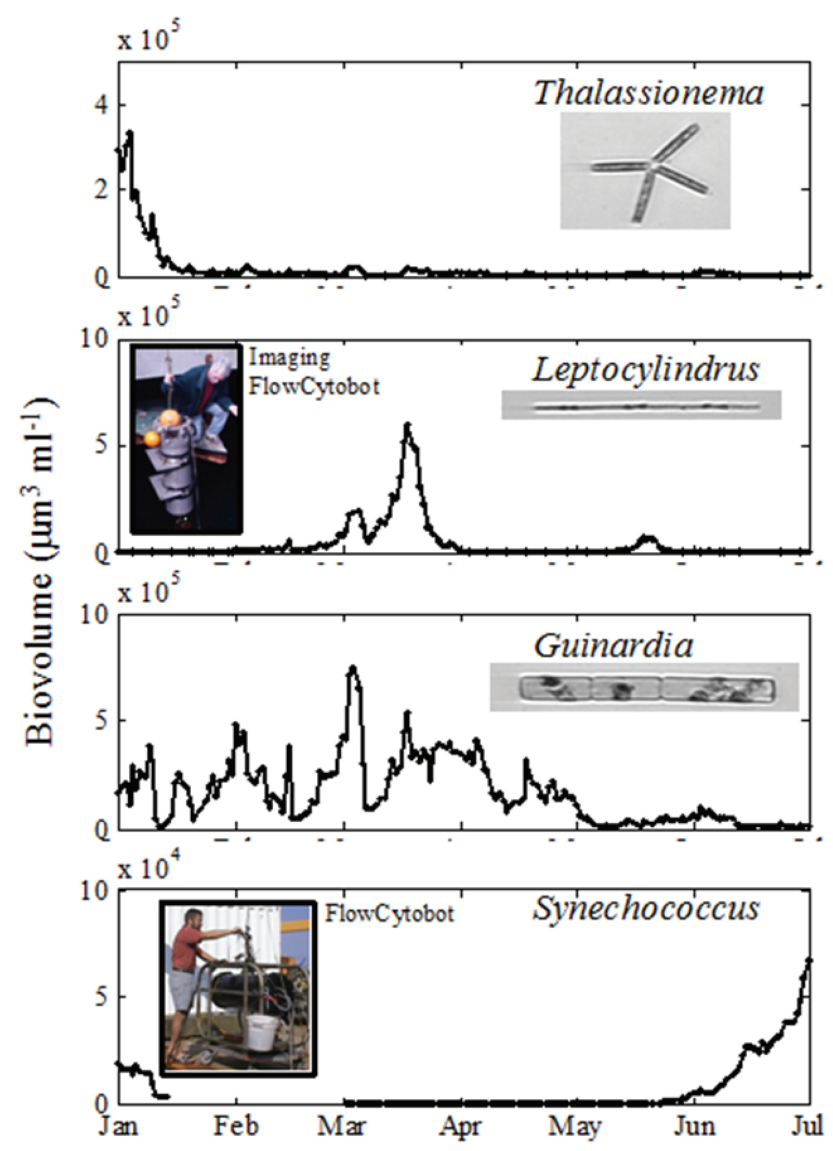

Fig. 5. Automated submersible flow cytometers are being used to generate high resolution time series of the phytoplankton community at the Martha's Vineyard Coastal Observatory. Two instruments, FlowCytobot (Olson et al., 2003) and Imaging FlowCytobot (Olson and Sosik, 2007), are deployed side-by-side for periods as long as 6 months (as shown here for early 2007) to measure single cells from pico- to microplankton. Upper three panels are from Imaging FlowCytobot and show variations in important diatoms quantified with automated image processing and classification (Sosik and Olson, 2007); bottom panel is from FlowCytobot measurements of light scattering and fluorescence from picocyanobacteria. Panels are shown with different ordinate scaling to emphasize differences temporal patterns among cell types. Source: Sosik and Olson (unpublished data), http://www.whoi.edu/mvco.

collected from discrete points. Because many problems in plankton ecology and marine particle optics involve processes that are highly variable in space and time, this limitation is serious and has motivated a long-standing interest in development of automated instruments with capabilities to perform outside the laboratory. Progress in this area has been made by several groups (Dubelaar and Gerritzen, 2000; Olson et al., 2003; Wang et al., 2005) and new measurement capabilities are emerging. These include spatial mapping with instruments deployed on underwater vehicles (Cunningham et al., 2003) and extended high resolution time series 
observations (Sosik et al., 2003; Thyssen et al., 2008). Essential adaptations for these applications include automated sample and data handling as well as on-board performance monitoring (e.g., standard bead analysis) and anti-fouling measures; these capabilities are emerging and providing unprecedented observations (Fig. 5).

Recently, in-flow cell imaging has emerged as a viable enhancement to submersible flow cytometry (Olson and Sosik, 2007). Previous work in the last decade demonstrated feasibility of integrating video imaging with flow cytometry in laboratory-based systems for study of plankton and other microbes (Sieracki et al., 1998; Kachel and Wietzorrek, 2000; Brehm-Stecher, 2007). When combined with the growing expertise in extended underwater flow cytometry and with new automated image analysis and classification approaches (e.g., Sosik and Olson, 2007), this capability can provide unique observations of plankton communities at ecologically relevant scales.

Other developing areas that may advance underwater applications are systems whose designs eliminate use of sheath fluid and flow cells (G. J. van den Engh, personal communication, 2008; Wang et al., 2005). These systems involve use of multiple light beams or position sensitive detectors to target particles in optical focus and have potential advantages for simple access to particles in natural suspension (e.g., eliminating the need to pump seawater into a pressure housing). Expanded measurement capabilities may also prove important, such as resolution of pulse shape (Dubelaar and Gerritzen, 2000) and laser Doppler velocimetry (Wang et al., 2005) for characterizing aspects of particle size and shape. In addition, continued investment in instrument designs that are smaller and require less power promise to expand the deployment capabilities of submersible flow cytometry.

\section{Other spectroscopic techniques}

A number of spectroscopic techniques are used in the laboratory and in industry for the identification of substances and determination of concentrations. Optical spectroscopic techniques have the advantages of being non-invasive and usually non-destructive, requiring no reagents and having high specificity. Recent technological advances in solid state excitation sources and detectors allow these techniques to be transitioned from the laboratory to the field. For example, laser Raman spectroscopy was once limited by large, unstable gas lasers and scanning spectrographs. Currently, handheld Raman systems using diode lasers and CCD chips are marketed for homeland security and drug enforcement applications.

\subsection{Laser induced breakdown spectroscopy (LIBS)}

Laser induced breakdown spectroscopy is a type of atomic emission spectroscopy. A high-power pulsed laser focused onto a target generates a plasma, which ablates only nanograms to picograms of material. The excited atoms spontaneously emit radiation as they fall back to a lower energy state, and the emitted spectrum is recorded. Thus LIBS is capable of determining the elemental composition of a target. LIBS possesses many of the characteristics required for in situ chemical sensing and is a promising technique for field measurements in extreme environments.

Researchers have examined the use of single and double pulse LIBS for analyzing bulk aqueous solutions (Pearman et al., 2003; Rai et al., 2003; De Giacomo et al., 2004b) and submerged solid targets (De Giacomo et al., 2004a, 2005, 2006, 2007). Laboratory experiments have also validated the LIBS technique in simulated deep ocean environments (pressure chambers) up to $2.76 \times 10^{7} \mathrm{~Pa}$ with both single and double pulse techniques (Lawrence-Snyder et al., 2006; Michel et al., 2007). Current results show more promising use of single pulse LIBS in high-pressure liquids due to the fact that the high pressures cause the laser-induced bubbles to collapse faster than occurs at atmospheric pressure (LawrenceSnyder et al., 2007). Many elements have been shown to be detectable in bulk aqueous solutions (e.g., $\mathrm{Na}, \mathrm{Ca}, \mathrm{Mn}, \mathrm{Mg}$, $\mathrm{K}$ and $\mathrm{Li}$ ) (Michel, 2007). However, while the technique has been validated in the laboratory and research is ongoing, no field instrument for oceanic analysis has been built to date.

\subsection{Laser Raman spectroscopy}

Laser Raman spectroscopy is a type of vibrational spectroscopy based on Raman scattering (inelastic scattering) that is capable of non-destructive molecular identification of solids, liquids and gases. It can measure multiple species simultaneously and requires no reagents or consumables, making it ideal for in situ long-term deployments. The Raman effect is essentially a wavelength shift in radiation scattered from molecular bonds. It was discovered by Raman and $\mathrm{Kr}$ ishnan (1928). Raman scattering theory is covered in detail in Nakamoto (1997), Lewis and Edwards (2001) and Ferraro et al. (2003), and in reviews such as Lyon et al. (1998).

A laser is used to excite a target, and the scattered, energyshifted radiation is recorded by a spectrometer. Standoff optics allow measurements to be made from behind pressure windows and at remote distances up to $66 \mathrm{~m}$ in air (Sharma et al., 2002). Many practical applications of this relatively weak effect ( 1 in $10^{8}$ photons are Raman scattered) developed rapidly after the advent of the laser which provides a powerful, stable, monochromatic excitation source; holographic transmissive gratings and notch filters for high signal-to-noise ratios in the scattered light; and charge coupled devices (CCDs) to image the entire Raman spectrum simultaneously (Chase, 1994; Owen et al., 1998; Adar, 2001). 
Trends in consumer electronics and recent interest in field portable systems for defense applications have greatly reduced the size and power consumption of current Raman systems.

Raman scattering is not wavelength dependent, however, Raman scattering intensity is inversely proportional to wavelength to the fourth power. Therefore a $532 \mathrm{~nm}$ wavelength laser will produce a 4.7 times stronger scattering intensity than the industry-preferred wavelength of $785 \mathrm{~nm}$ (given the same incident power). However, blue-green light can produce fluorescence in organic compounds, which can obscure the Raman signal. Both $532 \mathrm{~nm}$ (green) and $785 \mathrm{~nm}$ (red) Raman systems have been used, or are being developed, for oceanographic applications (Battaglia et al., 2004; Brewer et al., 2004; Kronfeldt et al., 2004).

Early oceanographic applications of Raman spectroscopy are decades old. Since the Raman spectrum of water is temperature dependent, the temperature of the surface ocean ( $<60 \mathrm{~m}$ depth in the open ocean) can be measured remotely (via aircraft) from the shape of the Raman water spectrum (Leonard et al., 1977, 1979; Becucci et al., 1999). The intensity of Raman water bands has also been used to determine the depth of laser penetration to correct airborne fluorescence measurements of phytoplankton (Bristow et al., 1981; Hoge and Swift, 1981) and to determine the thickness of hydrocarbon layers on the sea surface (Hengstermann and Reuter, 1990). More recently, interest has grown in the use of Raman spectroscopy for chemical measurements in the coastal ocean and deep sea. Raman spectroscopy is well suited to making measurements in the ocean because water is a relatively weak Raman scatterer (Williams and Collette, 2001). Attenuation in water is minimized by use of excitation wavelengths in the visible spectrum $(350-700 \mathrm{~nm})$; although at short working distances (i.e. centimeters), attenuation is not significant into the near UV and infrared.

A number of Raman instruments are currently being developed. The DORISS (Deep Ocean Raman In Situ Spectrometer) instrument is a commercial laboratory-model Raman instrument, using a $532 \mathrm{~nm}$ laser, modified for use in the ocean to depths of $4000 \mathrm{~m}$ (Brewer et al., 2004; Pasteris et al., 2004) (Fig. 6). DORISS has already been used to make a variety of in situ measurements of gases (Peltzer et al., 2004; White et al., 2006a), solids (White et al., 2005, 2006b), clathrate hydrates (Hester et al., 2006, 2007), and biological pigments (White et al., 2006b). A deep-sea system using $785 \mathrm{~nm}$ excitation light source is being developed for in situ monitoring of hydrothermal vent fluids (Battaglia et al., 2004). Development of that instrument is on-going (Dable et al., 2006). Raman spectroscopy is also a component of the MISPEC instrument - Multiparametric In-Situ Spectroscopic Measuring System for Coastal Monitoring (Kronfeldt et al., 2004).

In an effort to improve the sensitivity of in situ Raman sensors for measuring chemicals (such as polycyclic aromatic hydrocarbon compounds) in sea water, researchers are working on surface enhanced Raman scattering (SERS) tech-

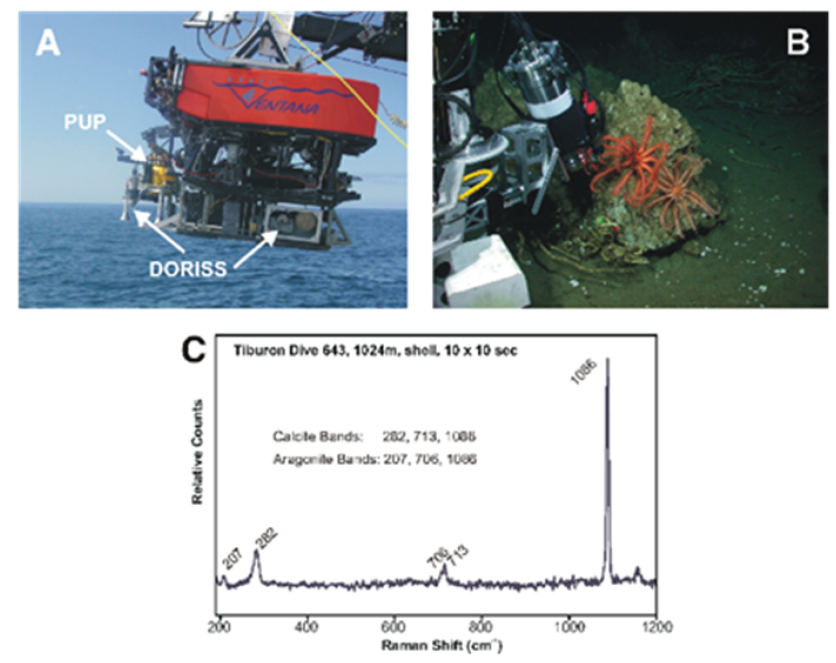

Fig. 6. (A) The DORISS instrument and the Prescision Underwater Positioner (PUP) are deployed by ROV (White et al., 2005). (B) The PUP is off-loaded on the seafloor and positions the DORISS optical head at a target of interest, such as this barite mound in Monterey Bay. (C) Raman spectroscopy is capable of in situ identification and differentiation of minerals on the seafloor, such as the calcium carbonates calcite and agragonite in a shell (White et al., 2005).

niques (Murphy et al., 1999, 2000; Bich Ha, 2004; Schmidt et al., 2004). In SERS, Raman intensities are enhanced by chemical and electromagnetic mechanisms when molecules are adsorbed onto specially prepared metal surfaces such as electrodes or metal colloidal particles (Moskovits, 1985). This is similar to surface plasmon resonance discussed in the next section.

While Raman spectroscopy and SERS have successfully been performed in the ocean, these instruments and techniques are still in the research stage. More work must be done to further refine the techniques and to address challenges such as robustness, fluorescence interference, improved sensitivity, and data processing methods.

\subsection{Surface plasmon resonance (SPR)}

Wood in 1902 observed that light reflected from gratings resulted in an unusual pattern of light and dark bands in the reflected spectrum (Wood, 1902). The theoretical basis for this effect was later developed to attribute these dark bands to surface plasmon waves created by the grating (Fano, 1941). Surface plasmons are transverse electromagnetic charge-density waves that propagate parallel to the interface between a dielectric medium and a metallic film. They are generated by the interaction between the electron-rich surface of the metal and a charged particle or photon. The light impinging at the interface between two transparent media of different refractive index is partly reflected and partly refracted. At the critical angle of incidence at the interface, total internal reflection of the light is observed. At this angle, 
the electromagnetic field component of the light penetrates a short distance ( $\sim$ tens or hundreds of nanometers) into the medium of lower refractive index, creating an evanescent wave. This produces surface plasmon resonance (SPR) due to the resonance energy transfer between the evanescent wave and the surface plasmons. The dielectric layer is typically either the sensing solution itself or an intermediate (functionalized) coating that attracts and binds only with specific (targeted) analytes. The point of resonance can be queried by varying the angle at which light impinges on the SPR sensing surface or by varying the wavelength to determine the point of total internal reflection. SPR spectroscopy has been employed for quantitative and qualitative analysis in a variety of biochemical, biomedical, and analytical chemistry fields (see Homola, 2006 for an excellent review of SPR sensing) and is also suitable to be applied to optical fiber sensors. While several commercial versions of SPR probes exist, to date no commercial in situ SPR probes are known to exist for submersible field probes. However, recent advances being made to increase the resolution and sensitivity in analyte detection show promise in utilizing SPR technology for in situ submersible sensing (e.g., Kim, et al., 2005; Slavik and Homola, 2006; Telezhnikova and Homola, 2006).

\section{Analyzers and compound instruments}

When optical sensors are coupled with a selective isolation or reaction process, selectivity can be enhanced for identification of in water materials - particularly in dissolved phase. Several manifestations currently exist in commercial embodiments.

\subsection{Reagent analyzers}

Analyzers combine reaction chemistry with absorbance or fluorescence measurement to determine indicators of water chemistry including nutrients, metals, and dissolved inorganic carbon products. Recent and current efforts in this arena span a wide range of measurable analytes, applications and embodiments Jannasch et al. (1994) developed a low power, extended deployment device using osmotic pumping. Researchers from the University of Southern Florida combined long-path capillary fiber absorption measurement with high spectral resolution spectrometer determination of nitrate and phosphate in oligotrophic basins (Ardonato, 2007). They also applied the same basic instrumentation to measurement of water $\mathrm{pH}$ (Liu, 2006) Hanson et al developed a contiuous flow system for concurrent real-time profiling of iron, nitorogen and other nutrients at $\mathrm{cm}$ resolution vertical scales (2000). This set of technologies was later adapted for operation on AUVs (Dickey, 2009). A growing suite of commercial analyzers now exist, extending from real-time to self contained extended deployment $(21,22,26,27,28)$. Some of these systems have undergone independent demonstration and evaluation (Alliance of Coastal Technologies, 2007).

\subsection{Membrane sensors}

The first usage of gas-permeable membranes for oceanographic application dates to the 1950s with introduction of the technique of Clark cells for the measurement of dissolved oxygen (Clark, 1958). Herein the membrane allows the analyte to diffuse from the sample water into the part of the cell in which the concentration is determined electrochemically. Like the Clark cell the Submersible Autonomous Moored Instrument for $\mathrm{CO}_{2}\left(\mathrm{SAMI}-\mathrm{CO}_{2}\right)$, developed by DeGrandpre (1995) in the 1990s, is a wet-chemical sensor, which makes use of a gas-permeable membrane separating the water from the fluid filled sensor volume. In contrast to the Clark cell, in which the analyte concentration is determined by means of an amperometric electrode, the SAMI measures the $\mathrm{CO}_{2}$ concentration using an optical method. Light is guided through the sensor volume filled with a $\mathrm{pH}$ sensitive indicator solution and its absorption is measured at three wavelengths. The wavelengths correspond to the absorbance maxima of the acid and base form of the indicator as well as a wavelength at which the solution shows no dependency on the $\mathrm{pH}$ value (DeGrandpre, 1995). This sensor has proven its functionality repeatedly (e.g., DeGrandpre, 1997, Körtzinger et al., 2008a, b) and it is commercially available (18). Another sensor system based on a technique very similar to the one of the SAMI is the Carbon Interface Ocean Atmosphere buoy, abbreviated CARIOCA (Merlivat et al., 1995). Many publications have been written on data collected by CARIOCA buoys as well as about intercomparison studies involving this sensor (e.g., http://www.lodyc.jussieu.fr/carioca), and a commercial version is available (25).

More recent developments in the field of membrane compound sensors have lead to the combined use of hydrophobic gas-permeable membranes with infrared absorption spectrometry. With permeability rates depending on the characteristics of the membrane, dissolved gas molecules in the water diffuse through this layer, which separates the outer water from the inner gas-volume of the sensor. This first step alone does not lead to a sensor being solely sensitive for a certain gas. The usage of a particular infrared wavelength leads to the unambiguous sensitivity of the sensor for the analyte provided that other phenomena associated with infrared spectrometry, such as water vapor cross sensitivity, are characterized. The wavelength used is matched to a certain vibrational mode of the target molecule. There are two known manufacturers for this membrane sensor type, whose products differ with respect to membrane design, possible analytes $\left(\mathrm{CH}_{4}\right.$, $\left.\mathrm{CO}_{2}\right)$, depth capability and response time $(6,14)$. The $\mathrm{CO}_{2}$ sensors of both manufacturers are currently under scientific investigation regarding their accuracy and possible usage for 
long-term deployment. An ACT evaluation of in situ $p \mathrm{CO}_{2}$ sensors is scheduled for 2009.

\subsection{Optodes}

Optode (or optrode) designs typically include an excitation source (e.g., light-emitting diodes - LEDs), a compoundimpregnated membrane on either a planar surface or optical fiber, and a photodetector to measure the emission response. It has long been known that certain fluorescing compounds experience dynamic fluorescence quenching (in intensity and lifetime) in the presence of oxygen (Kautsky, 1939). Numerous commercial manufacturers now use this principle for in situ detection of dissolved oxygen concentration $(1,21,23)$. A blue LED induces red fluorescence in a luminophore, and the intensity and lifetime of the fluorescence is dependent on oxygen concentration (e.g., Glud et al., 2000; Gouin et al., 1997; Tengberg et al., 2006). Planar oxygen optodes have been used in the water column on profiling floats (Körtzinger et al., 2004) and to make measurements in 2-dimensional space at benthic interfaces (e.g., Glud et al., 2001). Fiberoptic micro-optodes have been used around biological communities (Klimant et al., 1995; Gatti et al., 2002). Fluorescence quenching techniques have also been used to measure other properties such as $\mathrm{pH}$ (Hulth et al., 2002), and $\mathrm{H}_{2} \mathrm{~S}$ (Choi and Hawkins, 1997). Optodes have also been developed to measure salinity using SPR (Diaz-Herrera, et al., 2006) and density using refractometry (Marht and Hosseinioun, 1999).

\section{Looking forward}

It is easy to project a future in which optical measurements combine to provide a critical, universal and cross-cutting presence in modern observational oceanography. Within this context it is wise to consider the underlying drivers, the potentials, the common requirements, and the possible limitations in developing solutions.

As stated earlier, enabling technologies are major drivers for modern optical sensors evolution in ocean research. Major technology areas influencing optical sensor development include:

- material sciences such as microfabrication and nanotechnology;

- photonics, quantum optics and optoelectronics;

- information technology;

- multidisciplinary fields such as microfluidics and biophotonics.

Since ocean sensing forms a relatively small niche in the commercial market, it largely evolves through adopting new technologies driven by large sectors like the automotive, biomedical, or telecommunication industries. One prominent example of this influence is the availability of high power LEDs that form the bases of many optical instruments. Recent innovations in LEDs that are extending their spectral emission capabilities to $210 \mathrm{~nm}$ (Taniyasu, 2006). These sources will provide a low power and reduced size alternative to currently available xenon flash lamps and deuterium lamps in a wide range of applications (e.g., photometric nitrate detection or hydrocarbon fluorometers). Similarly the range and power of diode lasers continue to rapidly expand. More examples can be found in literally all aspects of optical sensors and will enable scientists and vendors alike to speed up development cycles and benefit from technologies they would otherwise not encounter. Conversely, the "pull" of larger industries also introduces drawbacks, such as rapidly changing product life cycles, periodic loss of availability, and limited overlap in terms of form factor, wavelength requirements, etc. Once again using the LED example, high power LEDs are widely available in the mid blue $(460 \mathrm{~nm})$, green $(520 \mathrm{~nm})$, orange $(590 \mathrm{~nm})$, and orange-red $(630 \mathrm{~nm})$ because of the automotive industry, but at other wavelengths (particularly some that are required for biological sensing) they are limited and typically have much lower output. In the extreme, this places developers in a position of designing to "what is available" as much as to "what is needed". The choices are further constrained in considering those innovations that are affordable. While it might prove technically feasible to place almost any technology into underwater use, the costs and risks associated with implementation and deployment make this impractical for many tools.

As uses evolve from immediate research interests to ongoing monitoring for societal welfare (e.g., public health, climate change, resource management), so must the state of the involved technologies, progress to meet operational requirements. In particular, long-term and ongoing monitoring programs typically have more stringent requirements for accuracy, repeatability, reliability, sensitivity and detection levels, ruggedness and resistance to fouling. These are still significant and ubiquitous challenges. Addressing these issues may be of higher relevance to resource managers and operational users than innovations for more specific proxies, unit cost and size, and many other benefits that enabling technologies potentially provide. In the end, the innovation and effort required to achieve attributes such as reliability and accuracy may far exceed those related to originally applying a new technology to a sensing method.

Enabling technologies continue to move the target of what is feasible. For example, fabrication of microelectromechanical systems (MEMS) provided us with a variety of sensors (e.g., modern accelerometers). A similar trend is now developing for nanoelectromechanical sensors. Ultimately size may be dominated by interfaces and other tertiary requirements and not the transducers, amplifiers and fluidic drivers performing the underlying measurements. 
In general "smaller", "more efficient" and "lower cost" are highly desirable attributes in looking forward, but they arguably are not the primary requirements for advancing the current state of the science and associated technologies. Issues such as fundamental performance (e.g. sensitivity, accuracy, stability), specificity in measurement, durability for extended use, and resistance to biofouling remain critical (and in many cases, unmet) challenges. It is vital that potential new advances in sensors address these fundamental needs. With that said, the vast and emerging suite of enabling core technologies provide researchers remarkable opportunities in addressing these issues.

Biofouling mitigation remains a cross-cutting requirement that requires special mention. Optical devices are particularly susceptible to the effects of biofouling due to coating and potential colonization of materials on optical windows and within flow chambers. The nature of the biofouling process is complex, and many approaches have been taken to minimize (never eliminating totally) their effects (see Lehaitre et al., 2008). The approaches have involved toxic paints, extensive use of copper cladding, "super slick" surfaces, charged surfaces and mechanical brushes and wipers. While efforts to reduce instrumental effects of fouling that have met with varying degrees of success, this problem remains a major concern in contemplating extended deployments of optical devices. Potential advances in methods, materials that self-clean or otherwise reject colonization might provide breakthrough advancements for the entire observing community. As with many other aspects of ocean sensors development, the issue of addressing biofouling stands to benefit and gain from technologies progress in other arenas. As examples, requirements for medical sciences, food handling and maritime shipping, are all driving possible solution paths that may prove applicable for optical sensors.

Generally speaking, most sophisticated laboratory methods can be transferred to field deployable, submersible instrumentation - if sufficient resources are available. This has already been done, for example, with mass spectrometers. To answer specific scientific questions and perform dedicated studies, this high-end instrumentation will sometimes be the only path forward; however, in operational monitoring, the number of highly complex sensors deployed will be limited compared to simpler and less specific sensors. This leads to potential uncertainties in applying estimates over broader temporal and spatial scales. How do we optimize the role of these sensors? In a sampling space-time continuum that spans several orders of magnitude (Dickey, 2005), how do we minimize sampling errors? Can we use complex sensors in concert with simpler, more densely spaced sensors to extend effective scales of coverage? Can we employ sensors in combinations to provide meaningful relationships with synoptic data from satellites, radar and airborne platforms? What role will models play in interpolating and extrapolating sensor data into environmental now-casts and forecasts?
These issues are deeply related to the concept of using optical sensors to establish sensor networks. Available smart sensors are combining the basic transducer with signal processing and network protocols. They incorporate intelligence that makes them more independent of additional supporting components and also provide built-in methods for quality control and sensor performance tracking. This built-in intelligence might also be used to detect phenomena of interest and adapt the measurement strategy appropriately. These features make smart sensors and smart instruments in general attractive for operational oceanography where long term operation and maintainability are amongst the main criteria. Because optical variability is strongly associated with environmental changes (e.g., temperature to name a simple one), combining different sensor data to gain value added information can also be important, especially for problems such as deriving biogeochemical parameters at synoptic scales from optical proxies. The power of using different sensors in networks not only allows extrapolation and interpolation, but also may provide vicarious calibration. What type of sensors might work together in this fashion? What levels of interoperability are required? What levels of absolute spatial and temporal coverage are required? These questions will form the basis for intriguing avenues of exploration in the coming years.

Given the long time-frames to bring sensors to operational status, more rapid methods are required to transition laboratory models and prototype sensors to mass production. Once again enabling technologies may play an important role in this process. Rapid prototyping tools, automated design and simulation packages, and modular components will all lead to more efficient development. That said, the community must work together if research to application timelines are to improve substantially. One important requirement is to provide standardization of instrument interfaces. This is especially true if new tools are to easily be tested and deployed in new observing infrastructures and sampling platforms (AUVs, glider, floats, etc.). Rapid development must also be accompanied by rigorous and systematic (field) testing to validate the long term reliability of sensors. Hand in hand with testing must come effective independent verification processes and development of effective protocols for use. This verification process, often overlooked in development plans, ultimately proves an essential step for new sensors to move beyond research novelties and into ongoing operational monitoring programs. While some programs now exist in the US, (e.g., ACT, ETV), this process is rarely considered by scientists, engineers, and agencies engaged in the early cycles of invention and discovery. As a result, gaps occur in funding, intellectual support wanes, and potential benefits from new technologies are delayed or lost. Weisberg et al. (2007) recently considered these issues in a study for the US Ocean Research and Resource Advisory Panel.

Progress in developing future optical tools for oceanographic applications will continue to be both responsive and 

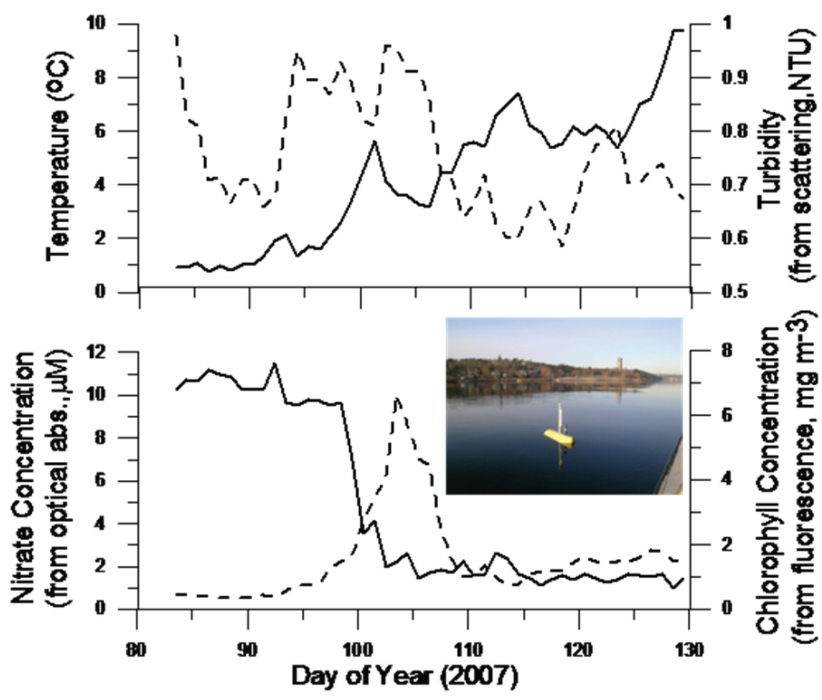

Fig. 7. Time-series of optical measurements during the spring phytoplankton bloom in a coastal embayment. Instruments were integrated and deployed aboard the Land-Ocean Biogeochemical Observatory (LOBO) platform in Halifax, Nova Scotia, Canada. The upper panel shows the temperature progression (solid) along with variation in the turbidity derived from optical scattering (dashed). The lower panel shows clearly the rapid increase in chlorophyll concentration (dashed) from fluorescence, which is mirrored by the consumption of nitrate, measured optically, which fuels the bloom.

subject to the advances in other technologies. The underlying physical principles for many optical measurements have been well described for decades, and advances with in-situ sensors will ensue as enabling technologies and established methodologies find workable pairings. Nonetheless, not all advances that are feasible will result in successful transition. The oceanographic sensor market is limited in size, small in numbers, restricted in its budget, and in general relies on public funding. Not all ideas can be supported for development, few will make it through to commercial transition, and few of those will prove viable as operational tools. In this respect, the recognized needs associated with societal issues will play as big a role as technological innovation in driving progress. Consequently, it is vital for potential operational users to clearly express requirements beyond cheaper, smaller, and better. Without clear specifications, gaps will persist between what developers are trying to accomplish and what consumers really need.

\section{Conclusions}

The progress and promise seen in the development of optical sensors in the past 10 years is significant. Consider the milestones achieved relative to these technologies. Oxygen optodes have been commercialized and are now widely used around the world. There are now a few commercial pro- ducers of sea-going flow cytometers, with a new generation in development. In situ excitation-relaxation fluorometers now are provided by multiple vendors and spectral fluorometers are becoming increasingly common. A new generation of commercial tools for looking at carbon related chemistry (e.g., POC, $p \mathrm{CO}_{2}$, $\mathrm{pH}$, methane) has emerged. Commercial optical sensors for nitrate now exist. Ten years ago, it was commonly perceived that optical sensors were not suitable for long term observations. Now they perform routinely in extended moored deployments and have recently been shown to provide viable measurements for three years on APEX profilers (e.g., Boss, 2008). Those familiar with this field may sometimes lament the pace of progress, but by any measure, optical sensors have begun to assume a role in modern oceanography.

While these milestones are of note, the community of ocean researchers and users has only begun to realize the potential of optical sensor technologies. New sensor technologies require decade-level time and support to see concepts to wide-scale adoption (Weisberg et al., 2007). With the notable exceptions of oxygen optodes, turbidity sensors, chlorophyll $a$ fluorometers, and possibly PAR sensors, most commercial sensors are still sold only for specific research niches, and have yet to reach the larger ocean monitoring community. Many of the technologies described in this article are still in developmental phases and are still years away from commercial realization. For those sensors that are commercialized there are still significant issues in assimilating them into the current ocean monitoring infrastructure. For turbidity sensors and single channel fluorometers, this is a relatively straight forward process. However, as the sensors become more complex so does the problem of integration. Beyond the basic challenges of coupling sensors into platforms and systems, there are other issues, such as production of data products appropriate for models, examination with other sampling methods and tools, and development of general usage protocols and expectations for accuracy, stability and other qualities that make a sensor widely useful. These are transition steps that must eventually be accomplished with all sensors if they are to serve in an operational capacity. A unique aspect for the case of optical sensors comes from the quantity and diversity of technologies involved. With the continued advancement of enabling technologies, the progress in the newer spectroscopic methods for sensors, and the growing demand for understanding ocean processes and providing effective resource management, the pressure for technology will only grow. It is important for the scientific community to understand that, as with the other aspects of development, effective adoption and transition is going to require qualified people and a consistent commitment of resources for years to come.

During his introductory remarks, a plenary presenter at a recent international Ocean Optics conference spoke of the potential suitability of renaming the gathering, "Ocean Optics and Biology". Optical sensors have given researchers 
biological sampling capabilities on the same time and space scales as physical measurements. The new generation sensors are now beginning to address the wide diversity of properties involved in understanding ecosystems (see also Kröger et al., 2009; Zielinski et al., 2009). In fact the speaker might have also included chemistry in his hypothetical title. Spectrophotometry coupled with reaction chemistry and semipermeable membranes, along with direct absorption processes have now allowed a direct observational link among biology, physics and chemistry. The simple example of observing nutrient drawdown during a seasonal phytoplankton bloom demonstrates the power of these linkages (Fig. 7).

With optical techniques one has the potential to estimate everything from temperature (Hickman, 1991; Fry, 2002) to salinity to dissolved gases and a long list of other constituents in water. This is not to say optical methods are optimal in all cases. It is rather to point out that in total, sensors incorporating optical techniques are filling increasingly significant roles in ocean monitoring and research, and their continued development remains a promising avenue of study with a growing base of applications.

Edited by: R. Prien

\section{References}

Aas, E. and Højerslev, N. K.: Analysis of underwater radiance observations: Apparent optical properties and analytical functions describing the angular radiance distribution, J. Geophys. Res., 104, 8015-8024, 1999

Adornato, L. R., Kaltenbacher, E. A., Greenhow, D. R., and Byrne, R. H.: High-Resolution/In Situ/Analysis of Nitrate and Phosphate in the Oligotrophic Ocean, Environ. Sci. Technol., 41, 4045-4052, 2007.

Alliance of Coastal Technologies (ACT): Protocols for Verifying the Performance of In Situ Chlorophyll Fluorometers. Alliance of Coastal Technologies, online available at: http://www.act-us. info/evaluation_reports.php, 2005.

Alliance of Coastal Technologies (ACT): Protocols for Verifying the Performance of In Situ Turbidity Sensor, Alliance of Coastal Technologies, online available at: http://www.act-us. info/evaluation_reports.php, 2006.

Alliance of Coastal Technologies (ACT): Protocols for Demonstrating the Performance of In Situ Nutrient Analyzers. Alliance of Coastal Technologies, online available at: http://www.act-us. info/evaluation_reports.php, 2007.

Adar, F.: Evolution and revolution of Raman instrumentation application of available technologies to spectroscopy and microscopy, in: Handbook of Raman spectroscopy: from the research laboratory to the process line, edited by: Lewis, I. R. and Edwards, H. G. M., Marcel Dekker, Inc., New York, 11-40, 2001.

Agrawal, Y. C.: The optical volume scattering function: temporal and vertical variability in the water column off the New Jersey Coast, Limnol. Oceanogr., 50, 1787-1794, 2005.

Babin, M.: Phytoplankton fluorescence: theory, current literature and in situ measurement, in: Real-time Coastal Observing Systems for Marine Ecosystem Dynamics and Harmful Al- gal Blooms: Theory, Instrumentation and Modelling, edited by: Babin, M., Roesler, C. S., and Cullen, J. J., UNESCO, Paris, 237-280, 2008.

Babin, M., Morel, A., and Gentili, B.: Remote sensing of sea surface sun-induced chlorophyll fluorescence: consequences of natural variations in the optical characteristics of phytoplankton and the quantum yield of chlorophyll $a$ fluorescence, Int. J. Remote Sens., 17, 2417-2448, 1996.

Bailey, S. W., Hooker, S .B., Antoine, D., Franz, B. A. , and Werdell, P. J.: Appl. Optics, 47, 2035-2045, 2008.

Balch, W. M., Drapeau, D. T., Bowler, B. C., Booth, E. S., Goes, J. I., Ashe, A., and Frye, J. M.: A multi-year record of hydrographic and bio-optical properties in the Gulf of Maine, I. Spatial and temporal variability, Prog. Oceanogr., 63, 57-98, 2004.

Bartz, R., Zaneveld, J. R. V., and Pak, H.: Transmission for profiling and moored observation in water, Ocean Optics V, International Society for Optical Engineering, 102-108, 1978.

Battaglia, T. M., Dunn, E. E., Lilley, M. D., Holloway, J., Dable, B. K., Marquardt, B. J., and Booksh, K. S.: Development of an in situ fiber optic Raman system to monitor hydrothermal vents, Analyst, 129(7), 602-606, 2004.

Becucci, M., Cavalieri, S., Eramo, R., Fini, L., and Materazzi, M.: Accuracy of remote sensing of water temperature by Raman spectroscopy, Appl. Optics, 38, 928-931, 1999.

Benfield, M. C., Grosjean, P., Culverhouse, P. F., Irigoien, X. M., Sieracki, E., Lopez-Urrutia, A., Dam, H. G., Hu, Q., Davis, C. S.,. Hansen, A, Pilskaln, C. H., Riseman, E. M., Schultz, H., Utgoff, P. E., and Gorsky, G.: RAPID: Research on automated plankton identification, Oceanography, 2(2), 172-187, 2007.

Beutler, M., Wiltshire, H. B., Meyer, K., Moldaenke, C., Lüring, C., Meyerhöfer, M., Hansen, U.-P, and Dau, H.: A fluorometric method for the differentiation of algal populations in vivo and in situ, Photosyn. Res. ,72, 39-53, 2002.

Bich Ha, N. T.: Surface-enhanced Raman scattering (SERS) for in-situ analysis of mixture of polycyclic aromatic hydrocarbons (PAH) in seawater, Doctoral Thesis, der Technischen Universität Berlin, Berlin, 2004.

Bishop, J. K. B.; Transmissometer measurement of POC, Deep-Sea Res., 46(2), 353-366, 1999.

Bishop, J., Davis, R. E., and Sherman, J. T.: Robotic observations of storm dust enhancement of carbon biomass in the North Pacific, Science, 298, 817-821, 2002.

Bogucki, D. J., Domaradzki, J. A., Anderson, C., Wijesekera, H. W., Zaneveld, R. V., and Moore, C.: Optical measurement of rates of dissipation of temperature variance due to oceanic turbulence, Opt. Express, 15, 7224-7230, 2007.

Boss, E., Perry, M. J., Swift, D., Taylor, L., Brickley, P., Zaneveld, J. R. V., and Riser, S.: Three years of ocean data from a biooptical profiling float, EOS, Transactions, American Geophysical Union, 89(23), 209-210, doi:10.1029/2008EO230001, 2008.

Brehm-Stecher, B.: New technologies for imaging individual microbial cells, in: Imaging cellular and molecular biological function, edited by: Frischknecht, F. and Shorte, S., Springer-Verlag, 307-337, 2007.

Brewer, P. G., Malby, G. E., Pasteris, J. D., White, S. N., Peltzer, E. T., Wopenka, B., Freeman, J., and Brown, M. O.: Development of a laser Raman spectrometer for deep-ocean science, Deep-Sea Res. I, 51, 739-753, doi:10.1016/j.dsr.2003.1011.1005, 2004.

Bristow, M., Nielson, D., Bundy, D., and Furtek, R.: Use of water 
Raman emission to correct airborne laser fluorosensor data for effects of water optical attenuation, Appl. Optics, 20, 2889-2906, 1981.

Bublitz, J., Dickenhausen, M., Grätz, M., Todt, S., and Schade W.: Fiber-optic laser-induced fluorescence probe for the detection of environmental pollutants, Appl. Optics 34, 3223-3233, 1995.

Campbell, L.: Flow cytometric analysis of autotrophic picoplankton, Methods in Microbiology: Marine Microbial Ecology, 30, Academic Press, 317-343, 2001.

Cavender-Bares, K. K., Frankel, S. L., and Chisholm, S. W.: A dual sheath flow cytometer for shipboard analyses of phytoplankton communities from the oligotrophic ocean, Limnol. Oceanogr., 43, 1383-1388, 1998.

Chang, G. C., Dickey, T., and Lewis, M.: Toward a global ocean system for measurements of optical properties using remote sensing and in situ observations, in: Remote Sensing of the Marine Environment: Manual of Remote Sensing, edited by: Gower, J., Vol. 6, Ch. 9, 285-326, 2006.

Chang, G., Mahoney, K., Briggs-Whitmore, A., Kohler, D., Mobley, C., Lewis, M., Moline, M., Boss, E., Kim, M., Philpot, W., and Dickey, T.: The new age of hyperspectral oceanography, Oceanography, 17, 16-23, 2004.

Chase, B.: A new generation of Raman instrumentation, Appl. Spectrosc., 48(7), 14A-18A, 1994.

Chekalyuk, A. M., Moore, K. A., White, D. L., and Porter, D. E.: Advaced Laser Fluorescence (ALF) Technology for Estrurine and Coastal Environmental Biomonitoring, Final Report submitted to NOAA/UNH Cooperative Institute for Coastal and Estuaring Environmental Technology (CICEET), 2006.

Chisholm, S. W., Armbrust, E. V., and Olson, R. J.: The individual cell in phytoplankton ecology: cell cycles and application of flow cytometry, in: Photosynthetic Picoplankton, edited by: Platt, T. and Li, W. K. W., Can. Bull. Fish. Aquat. Sci., 214, 343-369, 1986.

Chisholm, S. W., Olson, R. J., Zettler, E. R., Goericke, R., Waterbury, J., and Welschmeyer, N.: A novel free-living prochlorophyte abundant in the oceanic euphotic zone, Nature, 334, 340343, 1988.

Choi, M. F. and Hawkins, P.: Development of sulphide-selective optode membranes based on fluorescence quenching, Anal. Chim. Acta., 344, 105-110, 1997.

Clark Jr., L. C.: Patent No. 2913386, 17 November 1959.

Clark, C. D., Jimenez-Morais, J., Jones II, G., Zanardi-Lamardo, E., Moore, C. A., and Zika, R. G.: A time-resolved fluorescence study of dissolved organic matter in a riverine to marine transition zone, Marine Chem., 78, 121-135, 2002.

Claustre, H., Huot, Y., Obernosterer, I., Gentili, B., Tailliez, D., and Lewis, M.: Gross community production and metabolic balance in the South Pacific Gyre, using a non intrusive bio-optical method, Biogeosciences, 5, 463-474, 2008, http://www.biogeosciences.net/5/463/2008/.

Courties, C. and Troussellier, M.: Flow cytometry in the marine environment, Cytometry, 44, p. 163, 2001.

Cowles, T. J., Desiderio, R., and Neuer, S.: In situ characterization of phytoplankton from vertical profiles of fluorescence emission spectra, New York, Springer Verlag, Mar. Biol., 115(2), 217222, 1993.

Cullen, J. J.: Subsurface Layers of Phytoplankton: from the Deep Chlorophyll Maximum to Persistent Microscale Features, Ocean
Optics XVII Invited Lecture 25-29 October, (Comment in oral presentation) Fremantle, Australia, 2004.

Cunningham, A., McKee, D., Craig, S., Tarran, G., and Widdicombe, C.: Fine-scale variability in phytoplankton community structure and inherent optical properties measured from an autonomous underwater vehicle, J. Mar. Syst., 43, 51-59, 2003.

Dable, B. K., Love, B. K., Battaglia, T. M., Booksh, K. S., Lilley, M. D., and Marquardt, B. J.: Characterization and quantitation of a tertiary mixture of salts by Raman spectroscopy in simulated hydrothermal vent fluid, Appl. Spectrosc., 60(7), 773-780, 2006.

Daly, K. L., Byrne, R. H., Dickson, A. G., Gallager, S. M., Perry, M. J., and Tivey, M. K.: Chemical and biological sensors for timeseries research: current status and new directions, Mar. Technol. Soc. J., 38(2), 121-143, 2004.

Dana, D. R. and Maffione, R. A.: A New Hyperspectral Spherical Absorption Meter, Ocean Scinces 2006, 20-24 February, Honolulu, HI, 2006.

Davis, C. S., Gallager, S. M., Marra, M., and Stewart, W. K.: Rapid visualization of plankton abundances and taxonomic composition using the Video Plankton Recorder, Deep. Sea Res. I, 43(78), 1947-1970, 1996.

Davis, R. E., Eriksen C. E., and Jones, C. P.: Autonomous buoyancy-driven underwater gliders, in: The Technology and Applications of Autonomous Underwater Vehicles, edited by: Griffiths, G., Taylor and Francis, London, 37-58, 2002.

De Giacomo, A., Dell'Aglio, M., Casavola, A., Colonna, G., De Pascale, O., and Capitelli, M.: Elemental chemical analysis of submerged targets by double-pulse laser-induced breakdown spectroscopy, Anal. Bioanal. Chem, 385(2), 303-311, 2006.

De Giacomo, A., Dell' Aglio, M., Colao, F., and Fantoni, R.: Double pulse laser produced plasma on metallic target in seawater: basic aspects and analytical approach, Spectrochim. Acta B, 59, 14311438, 2004a.

De Giacomo, A., Dell'Aglio, M., Colao, F., Fantoni, R., and Lazic, V.: a. Double-pulse LIBS in bulk water and on submerged bronze samples, Appl. Surf. Sci., 247(1-4), 157-162, 2005.

De Giacomo, A., Dell'Aglio, M., and De Pascale, O.: Single pulse-laser induced breakdown spectroscopy in aqueous solution, Appl. Phys. A, 79(4-6), 1035-1038, 2004b.

De Giacomo, A., Dell'Aglio, M., De Pascale, O., and Capitelli, M.: From single pulse to double pulse ns-laser induced breakdown spectroscopy under water: Elemental analysis of aqueous solutions and submerged solid samples, Spectrochim. Acta B, 62(8), 721-738, 2007.

DeGrandpre, M. D., Hammar, T. R., Smith, S. P., and Sayles, F. L.: In situ measurements of seawater $p \mathrm{CO}_{2}$, Limnol. Oceanogr., 40(5), 969-975, 1995.

DeGrandpre, M. D., Hammar, T. R., Wallace, D. W. R., and Wirick, C. D.: Simultaneous mooring-based measurements of seawater $\mathrm{CO}_{2}$ and $\mathrm{O}_{2}$ off Cape Hatteras, North Carolina, Limnol. Oceanogr., 42(I), 21-28, 1997.

Diaz-Herrera, N., Esteban, O., Navarrete, M. C., Le Haitre, M., and Gonzalez-Cano, A.: In situ salinity measurements in seawater with a fibre-optic probe, Meas. Sci. Technol., 17, 2227-2232, 2006.

Dickey, T., Lewis, M., and Chang, G.: Optical oceanography: recent advances and future directions using global remote sensing and in situ observations, Rev. Geophys., 44, RG1001, doi:10.1029/2003RG000148, 2006. 
Dickey, T. D. and Bidigare, R. R.: Interdisciplinary oceanographic observations: the wave of the future, Scientia Marina, 69(Suppl. 1), 23-42, 2005.

Dickey, T. D., Itsweire, E. C., Moline, M., and Perry, M. J.: Introduction to the Limnol. Oceanogr., Special Issue on Autonomous and Lagrangian Platforms and Sensors (ALPS), Limnol. Oceanogr., 53(2), 2057-2061, 2008.

Donaghay, P. L., Sullivan, J. M., Moore, C., and Rhoades, B.: 4-D measurements of the fine scale structure of inherent optical properties in the coastal ocean, using the Ocean Response Coastal Analysis System (ORCAS), Proceedings from Ocean Optics XVI, 18-22, November Santa Fe, NM, 2002.

Donaghay, P. L. and Rines, J. E. B.: DURIP: Enhanced Characterization Optics for Ocean Response Analysis System (ECOORCAS), Office of Naval Research, Ocean Atmosphere Space, Fiscal Year 2005 Annual Reports, 2005.

Dubelaar, G. B. J. and Gerritzen P. L.: CytoBuoy: a step forward towards using flow cytometry in operational oceanography, Scientia Marina, 64, 255-265, 2000.

DuRand, M. D. and Olson, R. J.: Contributions of phytoplankton light scattering and cell concentration changes to diel variations in beam attenuation in the equatorial Pacific from flow cytometric measurements of pico-, ultra- and nanoplankton, Deep-Sea Res. II, 43, 891-906, 1996.

Fano, U.: The theory of anomalous diffraction gratings and of quasi-stationary waves on metallic surfaces (Sommerfeld's waves), J. Opt. Soc. Am., 31, p. 213, 1941.

Ferraro, J. R., Nakamoto, K., and Brown, C. W.: Introductory Raman Spectroscopy, Academic Press, San Diego, CA, 2003.

Frankel, S. L., Binder, B. B., Chisholm, S. W., and Shapiro, H. M.: A high-sensitivity flow cytometer for studying picoplankton, Limnol. Oceanogr., 35, 1164-1169, 1990.

Fry, E. S., Kattawar, G. W., and Pope, R.: Integrating cavity absorption meter, Appl. Optics, 31(12), 2055-2065, 1992.

Fry, E. S., Katz, J., Liu, D., and Walther, Th.: Temperature dependence of the Brillouin linewidth in water, J. Mod. Opt., 49, 411-418, 2002.

Gatti, S., Brey, T., Müller, W. E. G., Heilmayer, O., and Holst, G.: Oxygen microoptodes: a new tool for oxygen measurements in aquatic animal ecology, Mar. Biol., 140, 1075-1085, 2002.

Glud, R. N., Gundersen, J. K., and Ramsing, N. B.: Electrochemical and optical oxygen microsensors for in situ measurements, In: In Situ Monitoring of Aquatic Systems: Chemical Analysis and Speciatio, J. Buffle and G. Horvai, Eds. Wiley \& Sons. Chapter 2, 19-73, 2000.

Glud, R. N., Tengberg, A., Kühl, M., Hall, P. O. J., and Klimant, I.: An in situ instrument for planar $\mathrm{O}_{2}$ optode measurements at benthic interfaces, Limnol. Oceanogr., 46(8), 2073-2080, 2001.

Gordon, H. R.: In-orbit calibration strategy for ocean color sensors, Remote Sens. Environ., 63, 265-278, 1998

Gordon, H. R., Brown, O. B., and Jacobs, M. M.: Computed relations between the inherent and apparent optical properties of a flat homogeneous ocean, Appl. Optics, 14, 417-427, 1975.

Gouin, J. F., Baros, F., Birot D., and Andre, J. C.: A fibre-optic oxygen sensor for oceanography, Sensors and Actuators B, 3839, 401-406, 1997.

Green, R. E. and Sosik, H. M.: Analysis of apparent optical properties and ocean color models using measurements of seawater constitutents in New England continental shelf surface waters, J.
Geophys. Res., 109, C03026, doi:03010.01029/02003JC001977, 2004.

Green, R. E., Sosik, H. M., and Olson, R. J.: Contributions of phytoplankton and other particles to inherent optical properties in New England continental shelf waters, Limnol. Oceanogr., 48, 2377-2391, 2003.

Greenburg, A. E., Clesceri, L.S ., Eaton, A. E. (eds.): Standard Methods for the Examination of Water and Waste Water, 18th edition, American Public Health Association, 2-8-2-11, 1992.

Griffiths, G., Davis, R., Erikson, C., Frye, D., Marchand, P., and Dickey, T.: Towards new platform technology for sustained observations, in: Observing the Ocean for Climate in the 21 st Century, edited by: Koblinsky, C. J. and Smith, N. R. eds), GODAE, Australian Bureau of Meteorology, Melbourne, 324-338, 2001.

Haddock, S. H. D., Johnson, C., Orrico, C. M., Moline, M. A., and Case, J. F.: A multi-platform bathyphotometer for fine-scale, coastal bioluminescence research, Limnol. Oceanogr. Methods, 3, 247-262, 2005.

Haddock, S. H. D. and Case, J. F. : Bioluminescence spectra of shallow and deep-sea gelatinous zooplankton: ctenophores, medusae, and siphonophores, Mar. Biol., 133, 571-582, 1999.

Hanson, A. K. and Moore, C.: Real-Time Nutrient Surveys in Coastal Waters, Sea Technol., 42(9), 10-14, 2001.

Hengstermann, T. and Reuter, R.: Lidar fluorosensing of mineral oil spills on the sea surface, Appl. Optics, 29(22), 3218-3227, 1990.

Herren, C. M., Haddock, S. H. D., Johnson, C., Orrico, C. M., Moline, M. A., and Case, J. F.: A multi-platform bathyphotometer for fine-scale, coastal bioluminescence research, Limnol. Oceanogr. Methods, 3, 247-262, 2005.

Herring, P. J.: Systematic distribution of luminescent organisms, J. Biolum. Chemilum., 1, 147-163, 1987.

Hester, K. C., Dunk, R. M., White, S. N., Brewer, P. G., Peltzer, E. T., and Sloan, E. D.: Gas hydrate measurements at Hydrate Ridge using Raman spectroscopy, Geochim. Cosmochim. Acta, 71, 2947-2959, 2007.

Hester, K. C., White, S. N., Peltzer, E. T., Brewer, P. G., and Sloan, E. D.: Raman spectroscopic measurements of synthetic gas hydrates in the ocean, Mar. Chem., 98, 304-314, 2006.

Hickman, G. D., Harding, J. M., Carnes, M., Pressman, A., Kattawar, G. W., and Fry, E. S.: Aircraft laser sensing of sound velocity in water: Brillouin scattering, Remote Sens. Environ., 36, 165-178, 1991.

Hoge, F. E. and Swift, R. N.: Airborne simultaneous spectroscopic detection of laser-induced water Raman backscatter and fluorescence from chlorophyll a and other naturally occurring pigments, Appl. Optics, 20(17), 3197-3205, 1981.

Holliday, D. V.: Acoustical sensing of biology in the sea, in: Acoustical Oceanography, edited by: Leighton, T. G., Griffiths, H. D., and Griffiths, G., Proc. Inst. Acoustics., 23, 172-180, 2001.

Homola, J. (ed.): Surface Plasmon Resonance Based Sensors, Springer-Verlag Berlin and Heidelberg GmbH \& Co. K., 2006.

Hulth, S. Aller, R. C., Engström, P., and Selander, E.: A pH fluorosensor (optode) for early diagenetic studies of marine sediments, Limnol. Oceanogr., 47(1), 212-220, 2002.

Huot, Y., Brown, C. A., Cullen, J. J., et al: New algorithms for MODIS sun-induced chlorophyll fluorescence and a comparison with present data products, Limnol. Oceanogr. Methods, 3, 108130, 2005.

Jaffe, J. S.: Sensing plankton: acoustics and optical imaging, in: 
Real-time coastal observing systems for ecosystem dynamics and harmful algal blooms, edited by: Babin, M., Roesler, C. S., and Cullen, J. J., UNESCO, 385-394, 2008.

Jannasch, H. W., Johnson, K. S., and Sakamoto, C. M.: Submersible, osmotically pumped analyzers for continuous determination of nitrate in situ, Anal. Chem., 66, 3352-3361, 1994.

Jerlov, N. G.: Marine Optics, Elsevier Oceanography Series, 1978.

Jochem, F.: Probing the physiological state of phytoplankton at the single-cell level, Scientia Marina, 64, 183-195, 2000.

Johnson, K. S. and Coletti, L. J.: In situ ultraviolet spectrophotometry for high resolution and long-term monitoring of nitrate, bromide and bisulfide in the ocean, Deep-Sea Res. I, 49, 1291-1305, 2002.

Johnson, K. S., Coletti, L. J., and Chavez, F. P.: Diel nitrate cycles observed with in situ sensors predict monthly and annual new production, Deep Sea Res. I, 53, 561-573, $2006 .$.

Johnson, K. S., Needoba, J. A., Riser, S. C., and Showers, W. J.: Chemical sensor networks for the aquatic environment, Chem. Review, 107(2), 623-640, 2007.

Jonsson, P., Sillitoe, I., Dushaw, B., Nystuen, J., and Heltne, J.: Observing using sound and light - a short review of underwater acoustic and video-based methods, Ocean Sci. Discuss., 6, 819870,2009 ,

http://www.ocean-sci-discuss.net/6/819/2009/.

Kachel, V. and Wietzorrek, J.: Flow cytometry and integrated imaging, Scientia Marina, 64, 247-254, 2000.

Kautsky, H.: Quenching of luminescence by oxygen, T. Faraday Soc., 35, 216-219, 1939

Kim, Y., Banerji, S., Masson, J., Peng, W., and Booksh, K. S.: Fiber-optic surface plasmon resonance for vapor phase analyse, Analyst, 130, 838-843, 2005.

Kirk, J. T. O.: Light \& Photosynthesis in Aquatic Ecosystems, 2nd edition, Cambridge University Press, 1994.

Kirk, J. T. O.: Point-source integrating-cavity absorption meter: theoretical principles and numerical modeling, Appl. Optics, 36, 6123-6128, 1997.

Kirkpatrick, G. J., Millie, D. F., Lohrenz, S. E., Moline, M. A., Robbins, I., and Schofield, O.: An in situ sensor for phytoplankton community structure based on light absorption, AGU/ASLO/TOS Ocean Sciences, Honolulu, Hawaii, 2006.

Klimant, I., Meyer, V., and Kühl, M.: Fiber-optic oxygen microsensors, a new tool in aquatic biology, Limnol. Oceanogr., 40(6), 1159-1165, 1995.

Kolber, Z. S., Prasil, O., and Falkowski, P. G.: Measurements of variable chlorophyll fluorescence using fast repetition rate techniques: defining methodology and experimental protocols, Biochimi. Biophys. Acta, 1367, 88-106, 1998.

Körtzinger, A. J. Schimanski, and Send, U... High quality oxygen measurements from profiling floats: A promising new technique, J. Atmos. Ocean. Tech., 22, 302-308, 2004.

Körtzinger, A., Send, U., Lampitt, R. S., Hartman, S., Wallace, D. W. R., Karstensen, J., Villagarcia, M. G., Llina's, O., and DeGrandpre, M. D.: The seasonal $p \mathrm{CO}_{2}$ cycle at $49 \mathrm{~N} / 16.5$ $\mathrm{W}$ in the northeastern Atlantic Ocean and what it tells us about biological productivity, J. Geophys. Res., 113, C04020, doi:10.1029/2007JC004347, 2008a.

Körtzinger, A., Send, U.. Wallace, D. W. R., Kartensen, J., and DeGrandpre, M.: Seasonal cycle of $\mathrm{O}_{2}$ and $p \mathrm{CO}_{2}$ in the central Labrador Sea: Atmospheric, biological, and physical implications, Global Biogeochem. Cy., 22, GB1014, doi:10.1029/2007GB003029, 2008 b.

Kronfeldt, H.-D., Schmidt, H., Maiwald, M., Gallasch, L.-H., Konat-Stepowicz, J., Lehaître, M., LeNoac'h, A., Pfannkuche, J., Amann, H., Szymczak-Zyla, M., Filipowska, A., Lubecki, L., Kowalewska, G., Esteban-Martínez, O., Naverrete, M.-C., DíazHerrera, N., González-Cano, A., Bernabeu, E., Gibson, C., Mac Craith, B., Leclercq, M., and Roussel, B.: Multiparametric insitu spectroscopic, measuring system for coastal monitoring employed under field conditions in the Gulf of Gdansk, in: Proc. ISOPE, edited by: Matsui, T., Chung, J. S., Michel, J.-L., and Allersma, H., ISOPE, Toulon, France, 433-437, 2004.

Kröger, S., Parker, E. R., Metcalfe, J. D., Greenwood, N., Forster, R. M., Sivyer, D. B., and Pearce, D. J.: Sensors for observing ecosystem status, Ocean Sci., 5, 523-535, 2009, http://www.ocean-sci.net/5/523/2009/.

Lapota, D. and Losee, J. R.: Observations of bioluminescence in marine plankton from the sea of cortez, J. Exp. Mar. Biol. Ecol., 77, 209-240, 1984.

Lapota, D.: Long-term and seasonal changes in dinoflagellate bioluminescence in the Southern California Bight. Ph.D. thesis, University of California Santa Barbara, 1998.

Lapota, D.: Buoy-mounted bioluminescence sensor (BioBuoy) for special operations, Tech. Doc. 3155, Space and Naval Warfare Center, San Diego, CA, 142-145, 2003.

Lawrence-Snyder, M., Scaffidi, J., Angel, S. M., Michel, A. P. M., and Chave, A. D.: Laser-induced breakdown spectroscopy of high-pressure bulk aqueous solutions, Appl. Spectrosc., 60, 786790, 2006.

Lawrence-Snyder, M., Scaffidi, J., Angel, S. M., Michel, A. P. M., and Chave, A. D.: Sequential-pulse laser-induced breakdown spectroscopy of high-pressure bulk aqueous solutions, Appl. Spectrosc., 61, 171-176, 2007.

Lee, M. and Lewis, M. R.: A new method for the measurement of the optical volume scattering function in the upper ocean, J. Atmos. Ocean. Tech., 20, 563-571, 2003.

Leonard, D. A., Caputo, B., and Hoge, F. E.: Remote sensing of subsurface water temperature by Raman scattering, Appl. Optics, 18, 1732-1745, 1979.

Leonard, D. A., Caputo, B., and Johnson, R. L.: Experimental remote sensing of subsurface temperature in natural ocean water, Geophys. Res. Lett., 4, 279-281, 1977.

Lehaitre, M., Delauney, L., and Compère, C.: Biofouling and underwater measurements, Chapter 12, in: Real-Time Coastal Observing Systems for Marine Ecosystem Dynamics and Harmful Algal Blooms: Theory, instrumentation and modeling, edited by: Babin, M., Roesler, C. S., and Cullen, J. J., UNESCO Oceanographic Methodology Series, UNESCO Publishing, 2008.

Lewis, I. R. and Edwards, H. G. M. (eds.): Handbook of Raman Spectroscopy, Marcel Dekker, Inc., New York, 2001.

Lewis, M. R.: The measurement of apparent optical properties for the diagnosis of harmful algal blooms, in: Real-time Coastal Observing Systems for Marine Ecosystem Dynamics and Harmful Algal Blooms: Theory, Instrumentation and Modelling, edited by: Babin, M., Roesler, C. S., and Cullen, J. J., UNESCO, Paris, 207-236, 2008.

Li, W. K. W.: Shipboard analytical flow cytometry of oceanic ultraplankton, Cytometry, 10, 564-579, 1989.

Li, W. K. W. and Dickie, P. M.: Monitoring phytoplankton, bacte- 
rioplankton, and virioplankton in a coastal inlet (Bedford Basin) by flow cytometry, Cytometry, 44, 236-246, 2001.

Liu, X., Wang, Z., Byrne, R. H., Kaltenbacher, E. A., and Bernstein, R. E.: Spectrophotometric Measurements of $\mathrm{pH}$ in-Situ: Laboratory and Field Evaluations of Instrumental Performance, Environ. Sci. Technol., 40, 5036-5044, 2006.

Lyon, L. A., Keating, C. D., Fox, A. P., Baker, B. E., He, L., Nicewarner, S. R., Mulvaney, S. P., and Natan, M. J.: Raman spectroscopy, Anal. Chem., 70, 341R-361R, 1998.

Maffione, R. A. and Dana, D. R.: Instruments and methods for measuring the backward-scattering coefficient of ocean waters, Appl. Optics, 36, 6057-6067, 1997.

Mahrt, K.-H. and Hosseinioun, A.: Expendable high precision micro optical sensors to be used in automated concerted profilings for large area density contouring of the deep sea, Proc. MTS/IEEE Oceans 1999 (Seattle, WA), 3, 1218-1222, 1999.

Manov, D. V., Chang, G. C., and Dickey, T. D.: Methods for reducing biofouling of moored optical sensors, J. Atmos. Ocean. Tech., 21(6), 957-967, 2004.

Marie, D.,. Brussaard, C. P. D., Thyrhaug, R., Bratbak, G., and Vaulot, D.: Enumeration of marine viruses in culture and natural samples by flow cytometry, Appl. Environ. Microbiol., 65, 45-52, 1999.

Marie, D., Partensky, F., Jacquet, S., and Vaulot, D.: Enumeration and cell cycle analysis of natural populations of marine picoplankton by flow cytometry using the nucleic acid stain SYBR Green I, Appl. Environ. Microbiol., 63, 186-193, 1997.

Marie, D., Simon, N., and Vaulot, D.: Phytoplankton cell counting by flow cytometry, in: Algal culturing techniques, edited by: Andersen, R. A., Academic Press, 2005.

Merlivat, L. and Brault, P.: CARIOCA Buoy: Carbon Dioxide Monitor, Sea Technol., 10, 23-30, 1995.

Michel, A. P. M.: Laboratory evaluation of laser-induced breakdown spectroscopy as a new in situ chemical sensing technique for the deep ocean, Doctoral thesis, MIT/WHOI, Woods Hole, MA, 2007.

Michel, A. P. M., Lawrence-Snyder, M., Angel, S. M., and Chave, A. D.: Laser-induced breakdown spectroscopy of bulk aqueous solutions at oceanic pressures: evaluation of key measurement parameters, Appl. Optics, 46(13), 2507-2515, 2007.

Mitchell, B. G., Kahru, K., and Sherman, J.: Autonomous temperature-irradiance profiler resolves the spring bloom in the Sea of Japan, Proceedings of Ocean Optics XV, 16-20 October, Monaco, Office Naval Research, USA, CD-ROM, 2000.

Moore, C., Rhodes, B., Derr, A., and Zaneveld, R.: An instrument for hyperspectral characterization of inherent optical properties in natural waters, ASLO/TOS Ocean Research Conference 1520 February, Honolulu, HI, 2004.

Moore, C., Zaneveld J. R. V., and Kitchen J. C.: Preliminary results from an in situ spectral absorption meter, in: Ocean Optics XI, edited by: Gilbert, G. D., Proc. SPIE 1750, 330-337, 1992.

Moore, C., Twardowski, M. S., and Zaneveld, J. R. V.: The ECO VSF - A multi-angle scattering sensor for determination of the volume scattering function in the backward direction, Proceedings from Ocean Optics XV, 16-20 October, Monaco, 2000.

Moore, C., Da Cuhna, J., Rhoades, B., Twardowski, M. S., Zaneveld, J. R. V. and Dombroski, J... A new in-situ measurement and analysis system for excitation-emission fluorescence in natural waters, Proceedings of Ocean Optics XVII, 25-29 October,
Freemantle, Australia, 2004.

Moskovits, M.: Surface-enhanced spectroscopy, Rev. Mod. Phys., 57, 783-826, 1985

Mueller, J. L., Fargion, G. S., and McClain, C. R. (eds.): Ocean Optics Protocols For Satellite Ocean Color Sensor Validation, Revision 4, Volume IV: Inherent Optical Properties: Instruments, Characterization, Field Measurements and Data Analysis Protocols. NASA/TM-2003, 2003.

Murphy, T., Lucht, S., Schmidt, H., and Kronfeldt, H.-D.: Surfaceenhanced Raman scattering (SERS) system for continuous measurements of chemicals in sea-water, J. Raman Spectrosc., 31, 943-948, 2000.

Murphy, T., Schmidt, H., and Kronfeldt, H.-D.: Use of sol-gel techniques in the development of surface-enhanced Raman scattering (SERS) substrates for in situ detection of chemicals in seawater, Appl. Phys. B, 69, 147-150, 1999.

Nakamoto, K.: Infrared and Raman spectra of inorganic and coordination compounds: Part: A, John Wiley \& Sons, Inc., New York, 1997.

Olson, R. J., Chisholm, S. W., Zettler, E. R., Altabet, M. A., and Dusenberry, J. A.: a. Spatial and temporal distributions of prochlorophyte picoplankton in the North Atlantic Ocean. DeepSea Res. 37, 1033-1051, 1990a.

Olson, R. J., Chisholm, S. W., Zettler, E. R. and. Armbrust, E. V.: Analysis of Synechococcus pigment types in the sea using single and dual beam flow cytometry, Deep-Sea Res., 35, 425-440, 1988.

Olson, R. J., Chisholm, S. W., Zettler, E. R., and Armbrust. E. V.: Pigments, size, and distribution of Synechococcus in the North Atlantic and Pacific Oceans, Limnol. Oceanogr., 35, 4558, 1990b.

Olson, R. J., Shalapyonok, A. A., and Sosik, H. M.: An automated submersible flow cytometer for pico- and nanophytoplankton: FlowCytobot, Deep-Sea Res. I, 50, 301-315, 2003.

Olson, R. J. and Sosik, H. M.: A submersible imaging-in-flow instrument to analyze nano- and microplankton: Imaging FlowCytobot, Limnol. Oceanogr. Methods, 5, 195-203, 2007.

Olson, R. J., Sosik, H. M., and Chekalyuk, A. M.: Photosynthetic characteristics of marine phytoplankton from pumpduring-probe fluorometry of individual cells at sea, Cytometry, 37, 1-13, 1999.

Olson, R. J., Vaulot, D., and Chisholm, S. W.: Marine phytoplankton distributions measured using shipboard flow cytometry, Deep-Sea Res., 32, 1273-1280, 1985.

Olson, R. J., Zettler, E. R., and Anderson, O. K.: Discrimination of eukaryotic phytoplankton cell types from light scatter and autofluorescence properties measured by flow cytometry, Cytometry, 10, 636-643, 1989.

Olson, R. J., Zettler E. R., and Chisholm, S. W.: Advances in oceanography through flow cytometry, Particle analysis in oceanography, edited by: Demers, S., Verlag, 351-399, 1991.

Olson, R. J., Zettler, E. R., and DuRand, M. D.: Phytoplankton analysis using flow cytometry, in: Handbook of Methods in Aquatic Microbial Ecology, edited by: Kemp, P. F., Sherr, B. F., Sherr, E. B., and Cole, J. J., Lewis Publishers, 175-186, 1993.

Owen, H., Battery, D. E., Pelletier, M. J., Slater, J.: New spectroscopic instrument based on volume holographic optical elements, Proc. SPIE, 260-267, 1998.

Pasteris, J. D., Wopenka, B., Freeman, J. J., Brewer, P. G., White, S. 
N., Peltzer, E. T., and Malby, G. E.: Raman spectroscopy in the deep ocean: successes and challenges, Appl. Spectrosc., 58(7), 195A-208A, 2004.

Pearman, W., Scaffidi, J., and Angel, S. M.: Dual-pulse laserinduced breakdown spectroscopy in bulk aqueous solution with an orthogonal beam geometry, Appl. Optics, 42(30), 6085-6093, 2003.

Peltzer, E. T., White, S. N., Dunk, R. M., Brewer, P. G., Sherman, A. D., Schmidt, K., Hester, K. C., and Sloan, E. D.: In situ Raman analyses of natural gas and gas hydrates at Hydrate Ridge, Oregon. Eos Trans. AGU, 85(47), Fall Meet. Suppl., Abstract OS34B-01, 2004.

Petzold, T. J.: Volume Scattering Functions for Selected Ocean Waters, SIO Ref., Scripps Inst. of Oceanogr., La Jolla, Calif, 72-78, 79 pp., 1972.

Piontkovski, S. A., Williams, R., Peterson, W. T., Yunev, O. A., Minkina, N. I., Vladimirov, V. L., and Blinkov, A.: Spatial heterogeneity of the planktonic fields in the upper mixed layer of the open ocean, Mar. Ecol. Prog. Ser., 148, 145-154, 1997.

Prien, R.: The future of chemical in situ sensors, Mar. Chem., 107, 422-432, 2007.

Rai, V. N., Yueh, F.-Y., and Singh, J. P.: Study of laser-induced breakdown emission from liquid under double-pulse excitation, Appl. Optics, 42(12), 2094-2101, 2003.

Raman, C. V. and Krishnan, K. S.: A new type of secondary radiation, Nature, 121, 501-502, 1928.

Rayner, D. M. and Szabo, A. G.: Time-resolved laser fluorosensors: a laboratory study of their potential in the remote characterization of oil, Appl. Optics, 17, 1624-1630, 1978.

Reckermann, M.: Flow sorting in aquatic ecology, Scientia Marina, 64, 235-246, 2000.

Reckermann, M. and Colijn, F.: Aquatic flow cytometry: achievements and prospects, Forward, Scientia Marina, 64, 119-120, 2000.

Rohde, P., Busch, J. A., Henkel, R. H., Voss, D., and Zielinski, O.: Detection and identification of hydrocarbons in marine waters using time-resolved laser-fluorescence: Set-up and first results of a new submersible sensor, Oceans 2009 - Europe, 1-5, 2009.

Rose, J. M., Caron, D. A., Sieracki, M. E., and Poulton, N. J.: Counting heterotrophic nanoplanktonic protists in cultures and in aquatic communities by flow cytometry, Aquat. Microb. Ecol., 34, 263-277, 2004.

Roesler, C. S. and Boss, E.: In situ measurement of inherent optical properties and potential for harmful algal bloom detection and coastal ecosystem observations, in: Real-time Coastal Observing Systems for Marine Ecosystem Dynamics and Harmful Algal Blooms: Theory, Instrumentation and Modeling, edited by: Babin, M., Roesler, C. S., and Cullen, J. J., UNESCO, Paris, 153-206, 2008.

Röttgers, R. and Doerffer, R.: Measurements of optical absorption by chromophoric dissolved organic matter using a point-source integrating-cavity absorption meter, Limnol. Oceanogr. Methods, 5, 126-135, 2007.

Röttgers, R.: Comparison of different variable chlorophyll a fluorescence techniques to determine photosynthetic parameters of natural phytoplankton, Deep Sea Res. I, 54, 437-451, 2006.

Röttgers, R., Häse, C. and Doerffer, R.: Determination of the particulate absorption of microalgae using a point-source integratingcavity absorption meter: verification with a photometric tech- nique, improvements for pigment bleaching, and correction for chlorophyll fluorescence, Limnol. Oceanogr. Methods, 5, 1-12, 2007.

Ryder A. G.: Quantitative analysis of crude oils by fluorescence lifetime and steady state measurements using 380-nm excitation,. Appl. Spectrosc., 56, 107-116, 2002.

Sakamoto, C. M. Johnson, K. S., and Coletti, L. J.: Improved algorithm for the computation of nitrate concentrations in seawater using an in situ ultraviolet spectrophotometer, Limnol. Oceanogr. Methods, 7, 132-143, 2009.

Shapiro, H. M.: Practical flow cytometry, 4th ed. Wiley-Liss, 736 pp., 2003.

Schmidt, H., Bich Ha, N. T., Pfannkuche, J., Amann, H., Kronfeldt, H.-D., and Kowalewska, G.:. Detection of PAHs in seawater using surface-enhanced Raman scattering (SERS), Mar. Pollut. Bull., 49, 229-234, 2004.

Sharma, S. K., Angel, S. M., Ghosh, M., Hubble, H. W., and Lucey, P. G.: Remote pulsed laser Raman spectroscopy system for mineral analysis on planetary surfaces to 66 meters, Appl. Spectrosc., 56, 699-705, 2002.

Sieracki, C. K., Sieracki, M. E., and Yentsch, C. S.: An imagingin-flow system for automated analysis of marine microplankton, Mar. Ecol. Prog. Ser., 168, 285-296, 1998.

Slavík, R. and Homola, J.: Optical multilayers for LED-based surface plasmon resonance sensors, Appl. Optics, 45, 3752-3759, 2006.

Sosik, H. M.: Characterizing seawater constituents from optical properties, in: Real-time coastal observing systems for ecosystem dynamics and harmful algal blooms, edited by: Babin, M., Roesler, C. S., and Cullen, J. J., UNESCO, 281-329, 2008.

Sosik, H. M. and Olson, R. J.:. Phytoplankton and iron limitation of photosynthetic efficiency in the Southern Ocean during late summer, Deep-Sea Res. I, 49, 1195-1216, 2002.

Sosik, H. M. and Olson, R. J.: Automated taxonomic classification of phytoplankton sampled with imaging-in-flow cytometry, Limnol. Oceanogr. Methods, 5, 204-216, 2007.

Sosik, H. M., Olson, R. J., and Armbrust, E. V.: Flow cytometry in phytoplankton research, in: Chlorophyll a fluorescence in aquatic sciences: methods and applications, edited by: Suggett, D. J., Prasil, O., and Borowitzka, M. A., Springer, in press, 2009.

Sosik, H. M., Olson, R. J., Neubert, M. G. Shalapyonok, A. A., and Solow, A. R.: Growth rates of coastal phytoplankton from timeseries measurements with a submersible flow cytometer, Limnol. Oceanogr., 48, 1756-1765, 2003.

Taniyasu, Y., Kasu, M., and Makimoto, T.: An aluminium nitridelight- emitting diode with a wavelength of 210 nanometres, Nature, 441, 325-328, 2006.

Telezhnikova, O. and Homola, J.: New approach to spectroscopy of surface plasmons, Opt. Lett., 31, 3339-3341, 2006.

Tengberg, A., Hovdenes, J., Andersson, H. J., Brocandel, O., Diaz, R., Hebert, D., Arnerich, T., Huber, C., Körtzinger, A., Khripounoff, A., Rey, F., Rönning, C., Schimanski, J., Sommer, S., and Stangelmayer, A.: Evaluation of a lifetime-based optode to measure oxygen in aquatic systems, Limnol. Oceanogr. Methods, 4, 7-17, 2006.

Tzortziou, M. J., Herman, R., Gallegos, C. L., Neale, P. J., Subramaniam, A., Harding Jr., L. W., and Ahman, Z.: Bio-optics of the Chesapeake Bay from measurements and radiative transfer closure, Estuar. Coast. Shelf Sci., 68, 348-362, 2006. 
Thyssen, M., Tarran, G. A., Zubkov, M. V., Holland, R. J., Gregori, G., Burkill, P. H., and Denis, M.: The emergence of automated high frequency flow cytometry: revealing temporal and spatial phytoplankton variability, J. Plank. Res., 30, 333-343, 2008.

Twardowski, M. S., Lewis, M. R., Barnard, A. H., and Zaneveld, J. R. V.: In-water instrumentation and platforms for ocean color remote sensing applications, in: Remote Sensing of Coastal Aquatic Waters, edited by: Miller, R., Del-Castillo, C., and McKee, B., Kluwer Publishing, 69-93, 2005.

Twardowski, M. S., Zaneveld, J. R. V., and Moore, C.: A novel technique for determining beam attenuation compatible with a small sensor form factor and compact deployment platforms, Proceedings from Ocean Optics XVI, 18-22 November, Santa Fe NM, 2002.

Twardowski, M. S, Moore, C., Sullivan, J., Slivkoff, M., Freeman, S., and Zaneveld, J. R. V.: Volume Scattering Functions for Selected Ocean Waters: Revisited, in preparation, 2009.

Vaulot, D., Marie, D., Olson, R. J., and Chisholm, S. W.: Growth of Prochlorococcus, a Photosynthetic Prokaryote, in the Equatorial Pacific Ocean, Science, 268, 1480-1482, 1995.

Veldhuis, M., Kraay, G. W., and Timmermans, K. R.: Cell death in phytoplankton: correlation between changes in membrane permeability, photosynthetic activity, pigmentation and growth, Eur. J. Phycol., 36, 167-177, 2001.

Voss, K. J.: Use of the radiance distribution to measure the optional absorption coefficient in the ocean, Limnol. Oceanogr., 34, 1614-1622, 1989.

Voss, K. J. and Chapin, A. L.: Upwelling radiance distribution camera system, NURADS, Optics Express, 13, 4250-4262, 2005.

Voss, K. J. and Morel, A.: Bidirectional reflectance function for oceanic waters with varying chlorophyll concentrations: Measurements versus predictions, Limnol. Oceanogr., 50, 698-705, 2005.

Wang, X., Chan, R. K. Y., and Cheng, A. S. K.: Underwater cytometer for in situ measurement of marine phytoplankton by a technique combining laser-induced fluorescence and laser Doppler velocimetry, Opt. Lett., 30, 1087-1089, 2005.

Waters, K., Smith, R. C., and Lewis, M. R.: Avoiding ship-induced light-field perturbation in the determination of oceanic optical properties, Oceanography, 3, 18-21, 1990.

Weisberg, S. B., Covell, W., Dix, M. O., Hernandez, D., Matso, K., Moore, C., Reutter, J., and Schubel. J.: Best Practices For Increasing the Impact of Research Investments, Report from the Ocean Research and Resources Advisory Panel, Washington, DC, 2007.

Werdell, P. J. and Bailey, S. W.: An improved bio-optical data set for ocean color algorithm development and satellite data product validation, Remote Sens. Environ., 98, 122-140, 2005.

White, S. N., Brewer, P. G., and Peltzer, E. T.: Determination of gas bubble fractionation rates in the deep ocean by laser Raman spectroscopy, Mar. Chem., 99, 12-23, 2006a.

White, S. N., Dunk, R. M., Brewer, P. G., Peltzer, E. T., and Freeman, J. J.: In situ Raman analyses of deepsea hydrothermal and cold seep systems (Gorda Ridge \& Hydrate Ridge), Geochem. Geophy. Geosy., 7(5), Q05023, doi:05010.01029/02005GC001204, 2006b.

White, S. N., Kirkwood, W. J., Sherman, A. D., Brown, M. O., Henthorn, R., Salamy, K. A., Walz, P. M., Peltzer, E. T., and Brewer, P. G.: Development and deployment of a precision underwater positioning system for in situ laser Raman spectroscopy in the deep ocean, Deep Sea Res. I, 52, 2376-2389, 2005.

Widder, E. A.,. Case, J. F., Bernstein, S. A, MacIntyre, S. A., Lowenstine, M. R., Bowlby M. R., and Cook, D. P.: A new large volume bioluminescence bathyphotometer with defined turbulence excitation, Deep-Sea Res., 40(3), 607-627, 1993.

Widder, E. A. and Johnson, S.: Optical imaging, identification and 3D analysis of spatial distribution patterns of bioluminescent plankton: a map of the "minefield", J. Plankton. Res., 22, 409-420, 1998.

Widder, E. A., Frey, L., and Bowers, J.: Improved bioluminescence measurement instrument, Sea Technol., 46(2), 10-15, 2005.

Widder, E. A.: A look back at quantifying oceanic bioluminescence: Seeing the light, flashes of insight and other bad puns, Mar. Tech. Soc. J., 40(2), 136-137, 2006.

Williams, T. L. and Collette, T. W.: Environmental applications of Raman spectroscopy to aqueous systems, in: Handbook of Raman spectroscopy: from the research laboratory to the process line, edited by: Lewis, I. R. and Edwards, H. G. M., Marcel Dekker, Inc., New York, 683-731, 2001.

Wilson, T. and Hastings, J. W.: Bioluminescence, Annu. Rev. Cell Devel. Biol., 14, 197-230, 1998.

Wilson, S.: Launching the ARGO armada, Oceanus, 42, 17-19, 2000.

Wood, R. W.: On a remarkable case of uneven distribution of light in a diffraction grating spectrum, Philos. Magazine, 4, 396-402, 1902.

Yentsch, C. M.: Measurement of visible light absorption by particulate matter in the ocean, Limnol. Oceanogr., 7, 207-217, 1962.

Yentsch, C. M. and Horan, P. K.: Cytometry in the aquatic sciences, Cytometry, 10, 497-499, 1989.

Zaneveld, J. R. V.: Some aspects of the axially symmetric submarine daylight field, J. Geophys. Res., 77, 2677-2680, 1972.

Zaneveld, J. R. V. and Pegau, W. S.: Robust underwater visibility parameter, Opt. Express, 11, 2997-3009, 2003.

Zaneveld, J. R. V., Twardowski, M. S., Shifrin, K. S., Pegau, W. S., Boss, E., and Zolotov, I.: Inversion of light scattering measurements to obtain biogeochemical parameters, Plenary Presentation, Proceedings from Ocean Optics XVI, 18-22 November, Santa Fe, 2002.

Zaneveld, J. R. V., Spinrad, R. W., and Bartz, R.: Optical properties of turbidity standards, in: Ocean Optics VI, Proc. SPIE, 208, 159-168, 1979.

Zaneveld, J. R. V., Kitchen, J. C., and Moore, C.: Scattering error correction of reflecting tube absorption meters, in: Ocean Optics XII, edited by: Ackleson, S., Proc. SPIE, 2258, 44-55, 1994.

Zibordi, G., Hooker, S. B., Berthon, J. F., and D'Alimonte, D.: Autonomous above-water radiance measurements from an offshore platform: A field assessment experiment, J. Atmos. Ocean. Tech., 19, 808-819, 2002.

Zielinski, O., Busch, J. A., Cembella, A. D., Daly, K. L., Engelbrektsson, J., Hannides, A. K., and Schmidt, H.: Detecting marine hazardous substances and organisms: sensors for pollutants, toxins, and pathogens, Ocean Sci., 5, 329-349, 2009, http://www.ocean-sci.net/5/329/2009/.

Zielinski, O., Cembella, B., and Heuermann, R.: Bio-optical sensors onboard autonomous profiling floats. Proceedings of OMAE06: 25th International Conference on Offshore Mechanics and Artic Engineering, OMAE2006-92482, 735-739, 
doi:10.1115/OMAE2006-92482, 4-9 June 2006, Hamburg, 2006.

Zielinski, O., Fiedler, B., Heuermann, R., Körtzinger, A., Kopiske, E., Meinecke, G., and Munderloh, K.: A new nitrate continuous observation sensor for autonomous sub-surface applications: Technical design and first results, Oceans 2007 - Europe, 1-4, doi:10.1109/OCEANSE.2007.4302300, 2007.
Zubkov, M. V., and Burkhill, P. H.: Syringe pumped high speed flow cytometry of oceanic phytoplankton. Cytometry Part A 69A, 1010-1019, 2006.

Zubkov, M. V., Burkhill, P. H., and Topping, J. N.: Flow cytometric enumeration of DNA-stained oceanic planktonic protists, J. Plankon Res., 29, 79-86, 2007. 